\title{
CD73 AND CD29 CONCURRENTLY MEDIATE THE MECHANICALLY INDUCED DECREASE OF MIGRATORY CAPACITY OF MESENCHYMAL STROMAL CELLS
}

\author{
A. Ode ${ }^{1,2}$, J. Kopf ${ }^{1,3}$, A. Kurtz ${ }^{1}$, K. Schmidt-Bleek ${ }^{1}$, P. Schrade ${ }^{4}$, P. Kolar ${ }^{5}$, F. Buttgereit ${ }^{2,5}$, K. Lehmann ${ }^{1,2}$, \\ D. W. Hutmacher 6 , G. N. Duda ${ }^{1,2^{*}}$ and G. Kasper ${ }^{1,2}$
}

\author{
${ }^{1}$ Julius Wolff Institute and Musculoskeletal Research Center Berlin, Charité - Universitätsmedizin, Berlin, Germany \\ ${ }^{2}$ Berlin-Brandenburg Center for Regenerative Therapies, Berlin, Germany \\ ${ }^{3}$ Institute for Chemistry and Biochemistry, Freie Universität Berlin, Berlin, Germany \\ ${ }^{4}$ Institute of Vegetative Anatomy, Charité - Universitätsmedizin, Berlin, Germany \\ ${ }^{5}$ Department of Rheumatology and Clinical Immunology, Charité - Universitätsmedizin, Berlin, Germany
}

\begin{abstract}
The assumption that mesenchymal stromal cell (MSC)based-therapies are capable of augmenting physiological regeneration processes has fostered intensive basic and clinical research activities. However, to achieve sustained therapeutic success in vivo, not only the biological, but also the mechanical microenvironment of MSCs during these regeneration processes needs to be taken into account. This is especially important for e.g., bone fracture repair, since MSCs present at the fracture site undergo significant biomechanical stimulation. This study has therefore investigated cellular characteristics and the functional behaviour of MSCs in response to mechanical loading.

Our results demonstrated a reduced expression of MSC surface markers CD73 (ecto-5'-nucleotidase) and CD29 (integrin $\beta 1$ ) after loading. On the functional level, loading led to a reduced migration of MSCs. Both effects persisted for a week after the removal of the loading stimulus. Specific inhibition of CD73/CD29 demonstrated their substrate dependent involvement in MSC migration after loading. These results were supported by scanning electron microscopy images and phalloidin staining of actin filaments displaying less cell spreading, lamellipodia formation and actin accumulations. Moreover, focal adhesion kinase and Src-family kinases were identified as candidate downstream targets of CD73/CD29 that might contribute to the mechanically induced decrease in MSC migration.

These results suggest that MSC migration is controlled by $\mathrm{CD} 73 / \mathrm{CD} 29$, which in turn are regulated by mechanical stimulation of cells. We therefore speculate that MSCs migrate into the fracture site, become mechanically entrapped, and thereby accumulate to fulfil their regenerative functions.
\end{abstract}

Keywords: CD29, CD73, cytoskeleton, mechanical stimulation, migration, mesenchymal stromal cells.

*Address for correspondence:

Georg N. Duda

Julius Wolff Institute and Centre for Musculoskeletal Surgery

Charité - Universitätsmedizin Berlin

Augustenburger Platz 1

13353 Berlin, Germany

Telephone Number: +49 (030) 450659079

FAX Number: +49 (030) 450559969

E-mail: Georg.Duda@charite.de
Introduction

It is well accepted that mesenchymal stromal cells (MSCs) are key regulators in homeostasis and in a number of regenerative processes, possibly due to their capacity for self-renewal, multipotency, and, equally, their migratory and trophic activities. This includes their ability to home to tissue sites of repair or to participate in the remodelling response by providing a broad array of paracrine factors.

MSCs also hold great promise as tools for cell-based therapy and tissue engineering approaches. In numerous preclinical and clinical studies, MSCs have shown promising results for the treatment of cardiovascular and immune diseases as well as musculoskeletal injuries. One example of an injury is a bone fracture resulting in the formation of a haematoma, which is known to undergo regeneration while being mechanically strained. The amount of strain is determined by the interfragmentary movement - mainly axial compression (Goodship, 1992; Gardner et al., 1997). These mechanical conditions significantly influence the long-term bone healing outcome. A certain degree of movement is beneficial for fast and uneventful healing, whereas too little or too large movements can lead to so-called non-unions (Klein et al., 2003).

MSCs - key players in bone regeneration - are characterised by their multilineage differentiation capacity and their expression of a typical set of cell surface markers: CD29 (integrin $\beta 1$ ), involved in MSC migration in vivo (Ip et al., 2007); the homing receptor CD44 (hyaluronan receptor) (Zhu et al., 2006); the GPI-anchored proteins CD73 (ecto-5' -nucleotidase) and CD90 (Thy-1), signal transduction molecules in the human immune system and mediators of cell-cell and cell-matrix interactions (Hunsucker et al., 2005; Barker and Hagood, 2009); CD105 (endoglin), an integrin- and TGF- $\beta$-binding molecule (Eliceiri, 2001; Duff et al., 2003) and the adhesion molecules CD106 (VCAM-1) and CD166 (ALCAM) (Chamberlain et al., 2007).

Once MSCs have reached the fracture site - the first ones are evident $24 \mathrm{~h}$ after fracture (Phillips, 2005) - they are confronted with a challenging milieu characterised not only by low oxygen and low glucose content, but also by constant mechanical stress (Goodship and Kenwright, 1985; Komatsu and Hadjiargyrou, 2004). Importantly, the latter condition likely affects MSCs, which are known to be mechanosensitive (Wang and Thampatty, 2008). Thus, detailed knowledge about the influence of mechanical loading on MSCs is pivotal for understanding 
the physiological processes during bone regeneration in order to develop innovative cell therapy approaches. In recent studies, mechanical loading of MSCs under beneficial healing conditions in vitro, stimulated their expression of molecules that are involved in angiogenesis (Kasper et al., 2007a) and matrix remodelling (Kasper et al., 2007b) - key processes in bone regeneration. However, investigations regarding cell autonomous alterations in MSCs, specifically their MSC-characteristics and associated functional changes due to loading are still missing.

Therefore, our first aim was to analyse whether mechanical loading influences the criteria defining MSCs; i.e., their expression of typical cell surface markers and their ability to differentiate along the adipogenic, chondrogenic and osteogenic lineage. Our second aim - based on the first results - was to investigate whether changes in cell surface marker expression by mechanical loading would alter MSC functions, especially proliferation and migration.

While the differentiation potential was unaffected, CD73 and CD29 expression were found to be reduced. Both markers appeared to contribute to morphological changes and to a decrease in the migratory response after loading, possibly via FAK/Src family kinase (SFK)- and SFK-signalling. Moreover, the CD73 regulator TNF- $\alpha$ was increased and the CD29 regulator VEGF was decreased in response to loading.

\section{Materials and Methods}

\section{MSC isolation, culture and characterisation}

MSCs were isolated from bone marrow of 10-12 week old male Lewis rats and selected by plastic adherence (Dobson et al., 1999). Dulbecco's modified Eagle's medium (DMEM) (Gibco, NY, USA) supplemented with $10 \%$ foetal calf serum (FCS) (Biochrom AG, Berlin, Germany) and $10 \mathrm{U} / \mathrm{mL}$ penicillin plus $100 \mu \mathrm{g} / \mathrm{mL}$ streptomycin was used as expansion medium for MSCs. Only cells from passages 2-4 were used for experiments. The MSC-character was validated using flow cytometric analysis for MSC cell surface marker expression (positive: CD29, CD44, CD73, CD90, CD105, CD106 and CD166; negative: CD34, CD45, HLA-DR) and differentiation assays (Dominici et al., 2006).

For flow cytometry the following antibodies were employed: rabbit (anti-rat CD14), mouse (anti-rat CD34):FITC, rabbit (anti-rat CD105), and rabbit (antirat CD166) (Santa Cruz Biotechnology, Heidelberg, Germany), Armenian hamster (anti-rat CD29):FITC and mouse (anti-rat CD106) (Biolegend, San Diego, CA, USA), mouse (anti-rat CD45) and mouse (anti-rat CD90) (Acris Antibodies, Herford, Germany), mouse (anti-rat CD44) (AbD Serotec, Düsseldorf, Germany), mouse (anti-rat CD73) (BD Biosciences, Heidelberg, Germany), isotype Armenian hamster IgG:FITC (Biolegend), rat (antimouse IgG):PE (BD Biosciences) and donkey (anti-rabbit IgG):Cy5 (Dianova, Hamburg, Germany). Cells were analysed using FACSCalibur. Thirty thousand events were acquired and analysed using the FlowJo software.
To induce osteogenic and adipogenic differentiation, $1.92 \times 10^{4} \mathrm{MSCs}$ were cultured on 24 well plates and exposed to osteogenic (200 $\mu \mathrm{M}$ ascorbic acid, $7 \mathrm{mM}$ ß-glycerol phosphate, $0.01 \mu \mathrm{M}$ dexamethasone; $21 \mathrm{~d}$ ) and adipogenic differentiation media ( $1 \mu \mathrm{M}$ dexamethasone, $2 \mu \mathrm{M}$ insulin, $200 \mu \mathrm{M}$ indomethacin, $500 \mu \mathrm{M}$ isobutyl-methyl-xanthin; $16 \mathrm{~d})$. Osteogenic differentiation was detected by alizarin red staining. Adipogenic differentiation was determined by Sudan IV/haematoxylin staining. Each experiment was conducted in triplicate. For chondrogenic differentiation, a pellet culture in chondrogenic differentiation media (10 ng/mL TGF- $\beta 1,10^{-7} \mathrm{M}$ dexamethasone, $50 \mu \mathrm{g} / \mathrm{mL}$ ascorbic acid, $40 \mu \mathrm{g} / \mathrm{mL}$ proline, $100 \mu \mathrm{g} / \mathrm{mL}$ pyruvate, $6.25 \mu \mathrm{g} / \mathrm{mL}$ ITS, $1.25 \mathrm{mg} / \mathrm{mL}$ BSA, $5.35 \mathrm{mg} / \mathrm{mL}$ linoleic acid) as described was used for $28 \mathrm{~d}$ (Sekiya et al., 2002). Chondrogenic differentiation was detected by Alcian blue staining.

\section{Bioreactor experiments}

The bioreactor system used has been described previously (Matziolis et al., 2006). Briefly, MSCs were trypsinised, and $2 \times 10^{6}$ cells in $350 \mu \mathrm{L}$ of bioreactor medium (culture medium containing $2.4 \%$ Trasylol [Bayer, Leverkusen, Germany]) were mixed with $300 \mu \mathrm{L}$ of fibrinogen/ bioreactor medium (1:2) mixture and $50 \mu \mathrm{L}$ of thrombin $\mathrm{S} /$ bioreactor medium (1:2) mixture (Tissucol; Baxter, Munich, Germany). This MSC/fibrinogen/thrombin mixture was placed between two spongiosa bone chips and allowed to solidify for $30 \mathrm{~min}$ at $37^{\circ} \mathrm{C}$. The sandwich construct was placed into the bioreactor, and $25 \mathrm{~mL}$ of bioreactor medium was added. A strain of approximately $20 \%$ at a frequency of $1 \mathrm{~Hz}$ was applied in accordance with in vivo measurements of interfragmentary movement (Claes et al., 1998). Mechanical loading was carried out for $72 \mathrm{~h}$. Afterwards, cells within the fibrin construct were isolated by $225 \mathrm{U}$ trypsin/ $1 \mathrm{~mL}$ PBS. Equal levels of cell viability, activity and apoptosis between loaded and non-loaded MSCs were determined by the electronic cell counter system CASY ${ }^{\circledR}$ DT (Schaerfe System, Germany), a CellTiter96 AQueous test (MTS test; Promega, Mannheim, Germany) and an Annexin V:FITC assay kit (AbD Serotec, Düsseldorf, Germany), respectively. To determine whether the load-induced effects were persistent effects, loaded and non-loaded MSCs were re-embedded in fibrin and kept in non-loaded bioreactors for another six days. Each MTS test was conducted in triplicates.

\section{RNA isolation, cDNA synthesis, and quantitative Reverse Transcription-Polymerase Chain Reaction}

Total RNA was extracted using Trizol ${ }^{\circledR}$ Reagent (Invitrogen, Karlsruhe, Germany) and reversely transcribed to cDNA using iScript ${ }^{\mathrm{TM}}$ cDNA Synthesis kit (Bio-Rad, Munich, Germany) according to the manufacturer's instructions. RNA quality was evaluated by visualising the $18 \mathrm{~S} / 28 \mathrm{~S}$ rRNA on a $1.5 \%$ agarose gel. Quantification of the cell surface marker CD29 and CD73 were assessed by quantitative reverse transcription-polymerase chain reaction (qRT-PCR) using the $\mathrm{iQTM}$ SYBR ${ }^{\circledR}$ Green Supermix and the iQTM 5 Multicolor Realtime PCR Detection System and software (Bio-Rad) using the deltadelta-Ct-method. The transcript expression was normalised 
Table 1: Primer sequences

\begin{tabular}{|c|c|c|}
\hline Protein & Gene & Primer Sequence (forward / reverse) \\
\hline \multirow{2}{*}{ integrin beta 1 (CD29) } & \multirow{2}{*}{ Itgb } & 5' AATGGAGTGAATGGGACAGG 3' \\
\hline & & 5' TCTGTGAAGCCCAGAGGTTT 3' \\
\hline \multirow{2}{*}{ 5' ecto-nucleotidase (CD73) } & \multirow{2}{*}{ Nt5e } & 5' GCAAGGAAGAACCCAACGTA 3' \\
\hline & & 5' TCAGTCCTTCCACACCGTTA 3' \\
\hline \multirow{2}{*}{ actin cytoplasmic 1 ( $\beta$-actin) } & \multirow{2}{*}{ Actb } & 5' TGTCACCAACTGGGACGATA 3' \\
\hline & & 5' GGGGTGTTGAAGGTCTCAAA 3' \\
\hline \multirow{2}{*}{$\begin{array}{l}\text { glyceraldehyde-3-phosphate } \\
\text { dehydrogenase }\end{array}$} & \multirow{2}{*}{ Gapdh } & 5' ATGGGAAGCTGGTCATCAAC 3' \\
\hline & & 5' GTGGTTCACACCCATCACAA 3' \\
\hline \multirow{2}{*}{ elongation factor 1 -alpha 1} & \multirow{2}{*}{ Eefla } & 5' CCCTGTGGAAGTTTGAGACC 3' \\
\hline & & 5' CTGCCCGTTCTTGGAGATAC 3' \\
\hline
\end{tabular}

versus the housekeeping gene $\beta$-actin (Actb), elongation factor 1-alpha 1 (Eef1a), and glyceraldehyde-3-phosphate dehydrogenase $(G A P D H)$. The primers used in the realtime PCR assay were commercially purchased (Invitrogen; Table 1). Amplification efficiency (E) was assessed to be between 1.8 and 2. Transcripts from five MSC donors were analysed. Each experiment was conducted in triplicate.

\section{Transwell migration assay}

Random migration (i.e., equal concentrations of bioactive molecules in the both compartments) was measured by a modified Boyden chamber assay (Falk et al., 1980) using polycarbonate filters ( $8 \mu \mathrm{m}$ pore size; Nunc, Wiesbaden, Germany) coated with and without Collagen I (100 $\mu \mathrm{g} /$ $\mathrm{mL}$; Pure $\mathrm{Col} \AA$, Inamed Biomaterials, Fremont, CA, USA), which is the most abundant extracellular protein of bones (Rossert and de Crombrugghe, 2002). MSCs (4 $\left.\mathrm{x} 10^{4}\right)$ were seeded onto the filters and incubated for $5 \mathrm{~h}$ at $37^{\circ} \mathrm{C}$. Equal cell seeding was validated by an MTS test. Non-migrated cells were removed from the upper side of the filter by scraping, and remaining migrated cells were stained with $10 \mu \mathrm{g} / \mathrm{mL}$ Hoechst-33342 (Invitrogen). The average numbers of migrated cells from five microscopic fields $(1 \mathrm{~mm} \times 0.8 \mathrm{~mm})$ per filter $\left(0.47 \mathrm{~cm}^{2}\right)$ were analysed using the NIH ImageJ software package (http://rsb.info. nih.gov/nih-image/). Each experiment was conducted in duplicate.

\section{Blocking and induction assays}

A CD29 specific antibody, Armenian hamster (anti-rat CD29), (10 $\mu \mathrm{g} / \mathrm{mL}$; BD Biosciences), a CD73 inhibitor, adenosine 5'-( $\alpha, \beta$-methylene) diphosphate (APCP; 120 $\mu \mathrm{M}$; Sigma-Aldrich, Munich, Germany) and PP2 (10 $\mu \mathrm{M}$; Calbiochem, Merck KGaA, Darmstadt, Germany) were employed in migration assays. Each experiment was conducted in duplicate.

\section{Multiplex analysis and ELISA}

Multiplex analysis (Milliplex Rat Cytokine/Chemokine Panel Premix 24 Plex and Milliplex Rat Bone Panel
2; Millipore, Schwalbach, Germany) of conditioned media (CM) were performed by the manufacturer using duplicates. Enzyme-linked immunosorbent assays (ELISAs) (monoclonal antibodies for TNF- $\alpha$ and FAK (pTyr397) from R\&D Systems, Wiesbaden, Germany) were performed according to the manufacturer's instructions using triplicates. TNF- $\alpha$ was detected in 30-times concentrated CM. For standardisation, CM corresponding to equal cell numbers was applied. FAK (pTyr397) was detected in cell lysates and normalised to total protein content as determined by the Bio-Rad DC Protein Assay.

\section{Immunocytochemistry}

Staining of actin fibres of para-formaldehyde-fixed and permeabilised cells was achieved by incubation with Alexa 594-conjugated phalloidin (6.6 nM; Invitrogen). Nuclei were counterstained with $10 \mu \mathrm{g} / \mathrm{mL}$ Hoechst-33342 (Invitrogen). Each experiment was conducted in duplicate.

\section{Transmission electron microscopy}

MSCs in fibrin constructs were fixed with $2.5 \%$ glutaraldehyde in $0.1 \mathrm{M}$ sodium cacodylate buffer $(\mathrm{pH}$ 7.4). Specimens were post-fixed for $2 \mathrm{~h}$ in $2 \%$ osmium tetroxide at room temperature, followed by dehydration in a graded series of ethanol. Samples were immersed with propylene oxide as an intermedium, with a mixture of propylene oxide and epoxy resin, with pure epoxy resin and finally polymerised at $60^{\circ} \mathrm{C}$. Ultra-thin sections (70 $\mathrm{nm}$ ) were prepared with an ultra-microtome (Ultracut $\mathrm{S}$, Leica Microsystems, Wetzlar, Germany) and mounted on electron microscopy copper grids, 300 mesh. Sections were stained with uranyl acetate and lead citrate and investigated in the transmission electron microscope EM 906 (Zeiss, Oberkochen, Germany).

\section{Scanning electron microscopy}

MSCs in fibrin or on migration filters were fixed in 2.5 $\%$ glutaraldehyde in $0.1 \mathrm{M}$ sodium cacodylate buffer (pH 7.4). Samples underwent a graded ethanol series and 
A
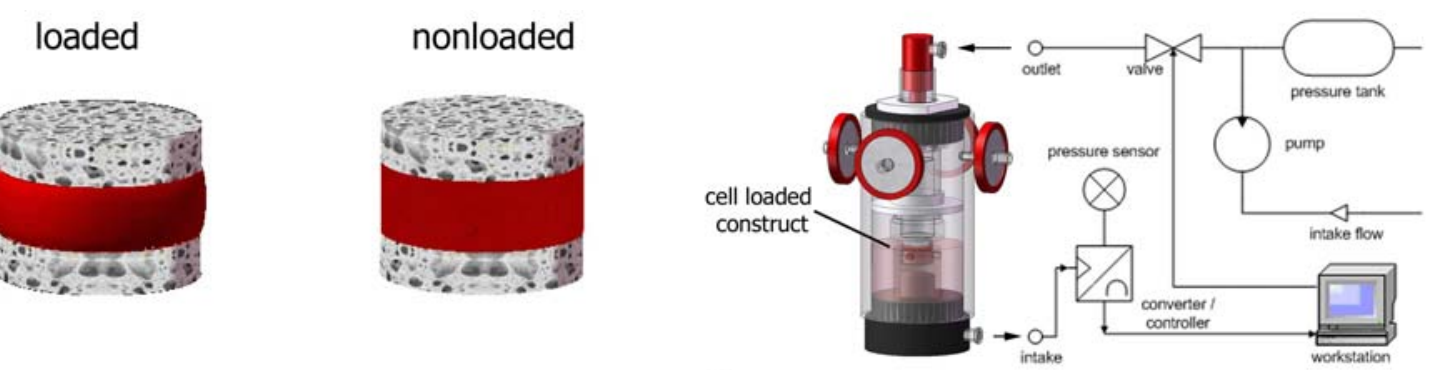

B

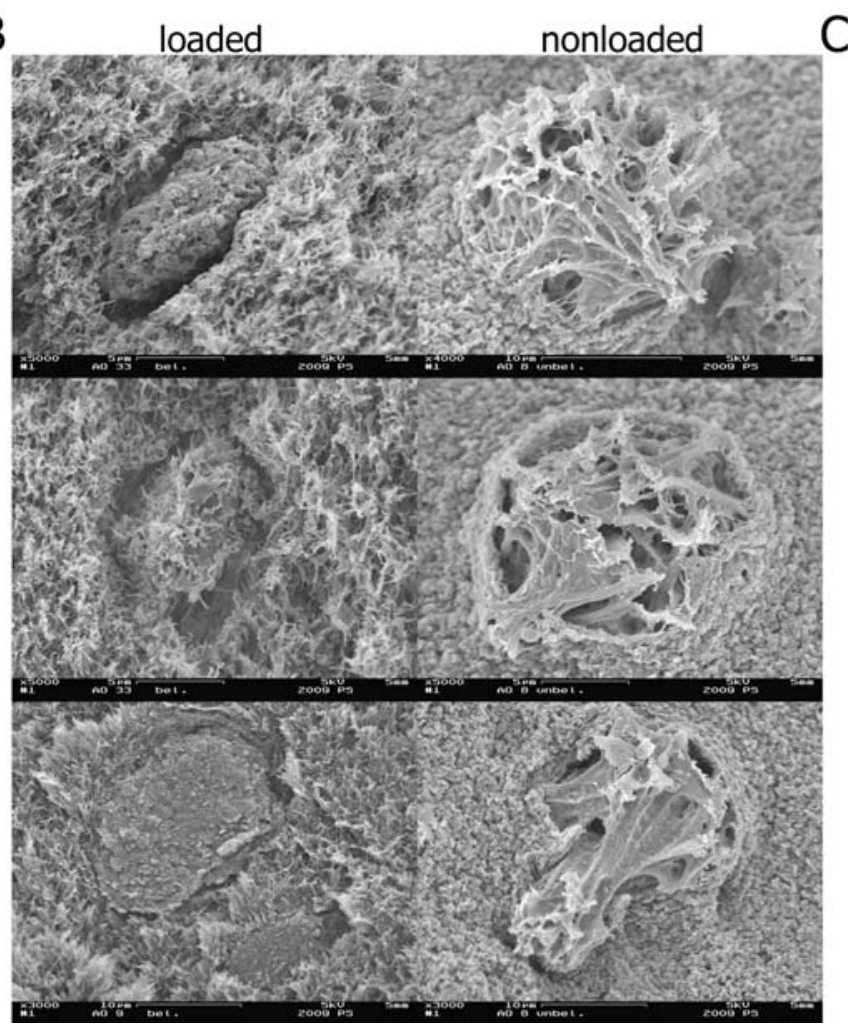

C loaded

nonloaded

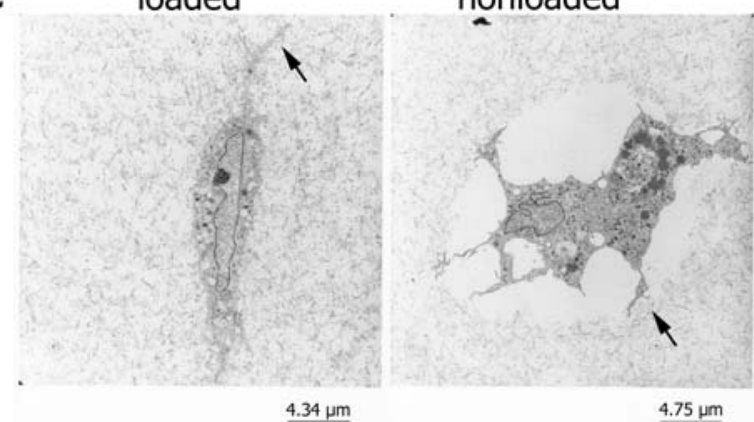

Fig. 1. Mechanical stimulation of MSCs embedded in a 3D fibrin construct. (A) Left: MSCs were embedded in fibrin, placed between two cancellous bone chips and mechanically stimulated. Shown are schematic pictures of loaded and non-loaded MSC/fibrin constructs. Right: Experimental set-up and control chart to investigate the effect of mechanical loading of MSC/fibrin constructs. (B) Shown are three representative pictures of loaded and non-loaded MSCs after three days detected by SEM. Note the differences in the 3D morphology and cell-fibrin interaction after loading. (C) Shown are loaded and non-loaded MSCs after three days detected by TEM.

were immersed in 100\% hexamethyldisilazane (HMDS) to replace the ethanol. Finally, samples were air dried under the fume hood overnight. Fibrin samples were mechanically fractured to investigate cells within the gel. Finished samples were mounted and fixed on aluminium stubs, and coated with gold/palladium using the MED 020 sputter coater (Baltec, Lichtenstein). SEM examination of the samples was performed using a Zeiss Digital Scanning Electron Microscope (DSM 982 Gemini, Zeiss). Each experiment of MSCs on migration filters was conducted in duplicate.

\section{Statistical analysis}

The SPSS 17.0 software package (SPSS Inc., Chicago, IL, USA) was used for statistical evaluation. If not stated otherwise, results from at least five independent experiments were analysed for statistical significance using the paired Student's $t$ test. The $t$-test assumption of normality was tested using the Shapiro-Wilk normality test. When performing multiple pair-wise comparisons, one-way or two-way analysis of variance (ANOVA, repeated measures) were performed, and $p$-values were adjusted using Bonferroni's $p$-value adjustment multiple comparison procedure. Results are presented as mean \pm standard deviation (SD). Gene expression data was statistically analysed using REST $^{\odot} 2008$ (Corbett Research/ Qiagen, Hilden, Germany) (Pfaffl et al., 2002). REST ${ }^{\odot}$ 2008 was developed by M. Pfaffl and Qiagen for exclusive analysis of gene expression data from quantitative real-time PCR experiments. Results are presented as median $\pm \mathrm{min} /$ max. A significance level was set at $p<0.05$.

\section{Results}

Characterisation of MSCs after mechanical loading In order to mechanically stimulate MSCs, a compression bioreactor system was employed to simulate loading 

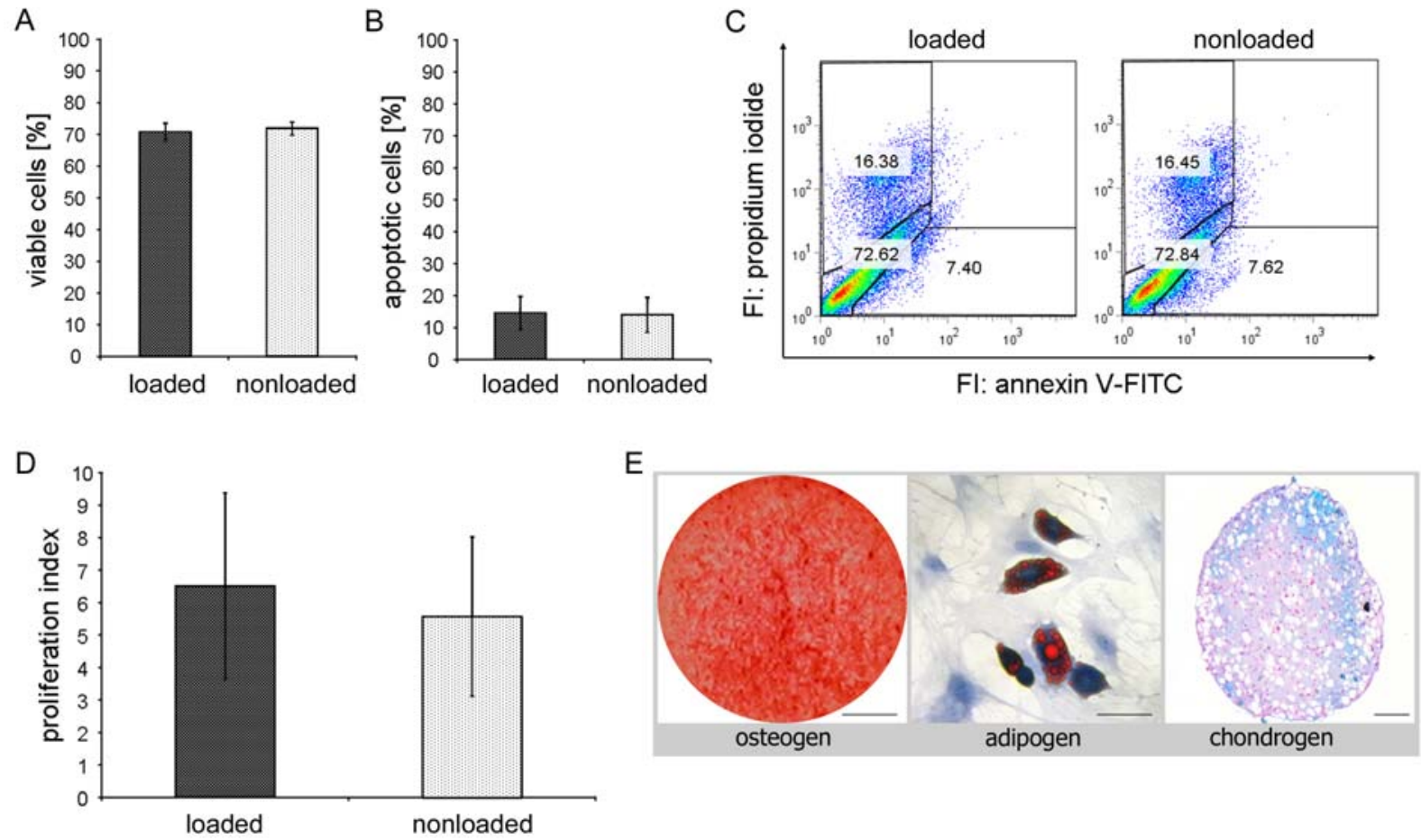

Fig. 2. Mechanically loaded MSCs show molecular and phenotypic characteristics of MSCs. After mechanical loading, the cells were isolated from the fibrin construct. (A) Cell viability was validated by means of CASY ${ }^{\circledR}$ Cell Counter Model DT. (B, C) Apoptotic cells were determined by double fluorescence staining with annexin V:FITC and propidium iodide and flow cytometry analysis. (B) Data analysis of flow cytometry data revealed no significant difference between loaded and non-loaded cells. (C) Shown are representative dot plots with relative fluorescence intensity of annexin V:FITC (x-axis) and relative fluorescence intensity of propidium iodide (y-axis) and appropriate gates determined with single colour staining. (D) Proliferation of loaded and non-loaded MSCs was determined by measuring cell activity on day one and six with the MTS test. The proliferation index was calculated by normalising day one to day six values. (E) MSCs could still differentiate into the adipogenic, chondrogenic and osteogenic lineage after loading. Bar indicates: $3 \mathrm{~mm}$ (osteogenic), $20 \mu \mathrm{m}$ (adipogenic), $100 \mu \mathrm{m}$ (chondrogenic). Abbreviations: FI, fluorescence intensity; FITC, fluorescein isothiocyanate $(n=5)$.

conditions determined in the fracture gap in vivo (Fig. 1A). SEM analyses of non-loaded MSCs embedded in fibrin revealed a round and wrinkled morphology with pronounced cell-fibrin interactions compared to an oval and almost smooth morphology of loaded MSCs with low cell-fibrin interactions (Fig.1B). TEM analyses further support these findings. In contrast to loaded MSCs, nonloaded MSCs seem to build more actin fibres (Fig. 1C). Cell activity analysis by MTS test revealed no significant difference between loaded and non-loaded MSCs (OD 490 $\mathrm{nm}:$ mean $_{\text {loaded }}=1.359$, mean $\left._{\text {non-loaded }}=1.337 ; p=0.963\right)$. An equal number of viable cell in constructs exposed to mechanical loading and non-loaded controls was validated by means of CASY ${ }^{\circledR}$ Cell Counter Model DT (cell viability: mean $_{\text {loaded }}=70.7 \%$, mean non-loaded $=71.8 \% ; p=0.488$; Fig. 2A). Annexin V/PI staining revealed no significant difference in the number of apoptotic cells between loaded and non-loaded MSCs (percentage of apoptotic cells: mean $_{\text {loaded }}=14.3 \%$, mean non-loaded $=13.9 \% ; p=0.094$; Fig. 2B,C). Proliferation was unaffected by mechanical stimulation (cell activity day 7 normalised to day 1: mean $_{\text {loaded }}=6.5$, mean $_{\text {non-loaded }}=5.6 ; p=0.199$; Fig. 2D). Loaded and non-loaded MSCs were able to differentiate towards the adipogenic, chondrogenic and osteogenic lineage (Fig. 2E), and quantitative analysis revealed an increase in chondrogenic, but no difference in adipogenic and osteogenic differentiation capacity after loading. After cultivation in appropriate differentiation media, chondrogenic differentiation ability was significantly increased after mechanical loading (area Alcian Blue: loaded $=53.0 \%$, unloaded $=39.4 \%, p=0.040$ ).

\section{CD29 and CD73 are downregulated in response to mechanical loading}

In order to investigate whether mechanical loading affects the MSC characteristics, their cell surface marker expression pattern was determined. Qualitatively, the markers CD29, CD44, CD73, CD90, CD105, CD106 and CD166 were still expressed on loaded MSCs. The analysed populations were homogenous with no subpopulations detectable. Quantitatively, cyclic-compressive loading led to a significant downregulation of CD29 (CD29 mean fluorescence intensity (MFI) normalised to the isotype control: ratio $_{\text {loaded }}=5.09$, ratio $_{\text {non-loaded }}=7.03 ; p=0.021$ ) and CD73 compared to the non-loaded controls (CD73 MFI normalised to the isotype control: ratio $_{\text {loaded }}=2.35$, ratio $_{\text {non-loaded }}=5.04 ; p=0.017$; (Fig. 3A). To analyse whether the apparent marker regulation also occurs on the mRNA level, quantitative RT-PCR analyses were performed. In accordance with flow cytometry data, also CD29 and 


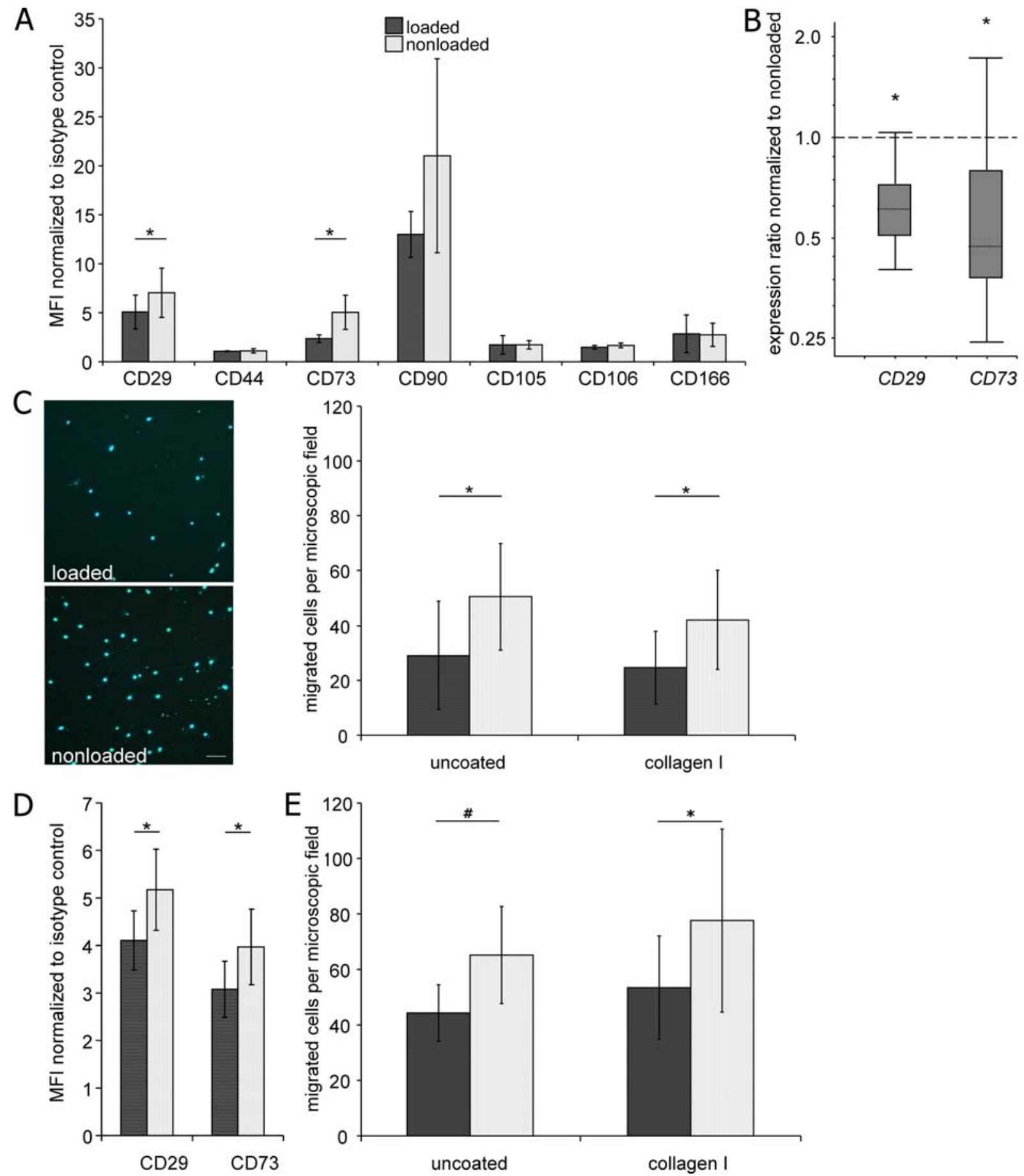

Fig. 3. CD29 and CD73 are downregulated and migration is reduced in mechanically loaded and non-loaded MSCs (A) The expression of MSC cell surface markers of loaded and non-loaded MSCs was investigated by flow cytometry. Shown is the mean fluorescence intensity (MFI) of loaded and non-loaded MSCs stained with specific Abs after normalisation to isotype controls. (B) The expression of mRNA specific for CD29 and CD73 of loaded and non-loaded MSCs was evaluated by quantitative reverse transcription-polymerase chain reaction and normalised for the housekeeping genes Actb, Gapdh and Eef1a. Shown is the gene expression of loaded MSCs normalised to non-loaded MSCs. Results are presented as medians with the whiskers indicating the min-max range. (C) MSC migration was investigated in a modified Boyden-Chamber assay on migration filters either uncoated or coated with collagen type I. The numbers of migrated cells from five microscopic fields per filter were analysed using NIH ImageJ software. Two representative pictures of migrated loaded and non-loaded cells and the average number of migrated cells per microscopic field (after five hours) are shown. Bar indicates $50 \mu \mathrm{m}$. (D, E) To determine whether the observed effects are persistent results, the cells were re-embedded in fibrin and kept in non-loaded bioreactors for another six days. (D) The expression of CD73 and CD29 of loaded and non-loaded MSCs was investigated by flow cytometry. (E) MSC migration was investigated in a modified Boyden-Chamber assay on migration filters either uncoated or coated with collagen type I. $\left(n=5, \#, p=0.049\right.$ without Bonferroni correction; $\left.{ }^{*}, p<0.05\right)$. 

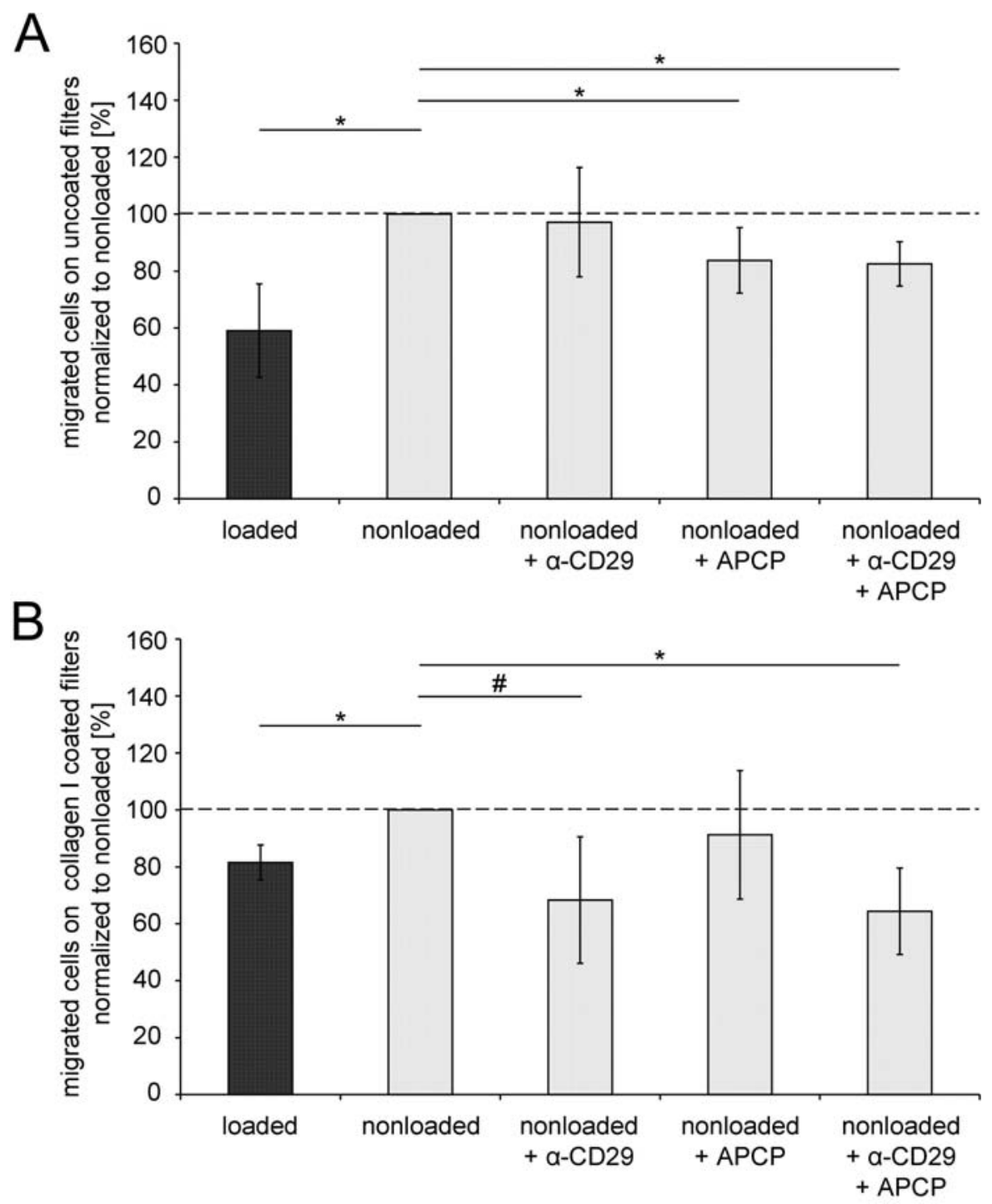

Fig. 4. Inhibition of CD29 and CD73 leads to reduced migration of MSCs on collagen type I and uncoated migration filters, respectively. Migration of loaded and non-loaded MSCs on (A) uncoated and (B) collagen I coated filters was investigated in the presence of CD29 blocking antibody $(10 \mu \mathrm{g} / \mathrm{mL})$ and $120 \mu \mathrm{M}$ APCP. Shown is the number of migrated cells after five hours normalised to non-loaded MSCs $(n=5, \#, p=0.051$ without Bonferroni correction; $*, p<0.05)$.

CD73 mRNA expression in MSCs was significantly downregulated in response to mechanical loading (relative gene expression normalised to the non-loaded control: $\mathrm{E}_{C D 29}=0.618 ; p=0.031 ; \mathrm{E}_{C D 73}=0.433 ; p=0.013$; Fig. 3B).

\footnotetext{
Migratory capacity is reduced after mechanical loading

Most cells, if not all, retain autochthonous cytoskeletal oscillation, polarity, and random migration in the absence of pro-migratory factors (Friedl, 2004). Random migration of MSCs can be stimulated by non-directional motogenic signals, such as the uniform application of the plateletderived growth factor (PDGF) (Ozaki et al., 2007). Since CD29 and CD73 are both associated with cell migration, the influence of cyclic-compressive loading on this MSC function was further investigated. MSC migration decreased significantly in response to loading, but was unaffected by coating (loading: $p<0.001$; coating: $p=$
}

0.373; migrated cells per microscopic field: mean ${ }_{\text {loaded, }}$ collagen type $\mathrm{I}=24.7$ cells, mean $_{\text {non-loaded, collagen type I }}=42.0$ cells, $p<0.001 ;$ mean $_{1}=29.1$ cells, mean

$=50.46$ cells, $p<0.001$ ) (Fig. $3 \mathrm{C}$ ). These numbers of migrated cells correspond to a random migration rate of 4-11\%, which is in line with the literature (Rüster et al., 2005; Thibault et al., 2007).

\section{Reduced CD29 and CD73 expression and migratory capacity remain after removal of mechanical stimulus}

Subsequently, the question arose whether the downregulation of CD29 and CD73 as well as the reduction in the migratory capacity were persistent effects. To address that issue, MSCs were loaded for three days and kept non-loaded for another six days. CD29 and CD73 protein expression was still significantly downregulated in loaded compared to non-loaded MSCs (CD29 MFI normalised to the isotype 


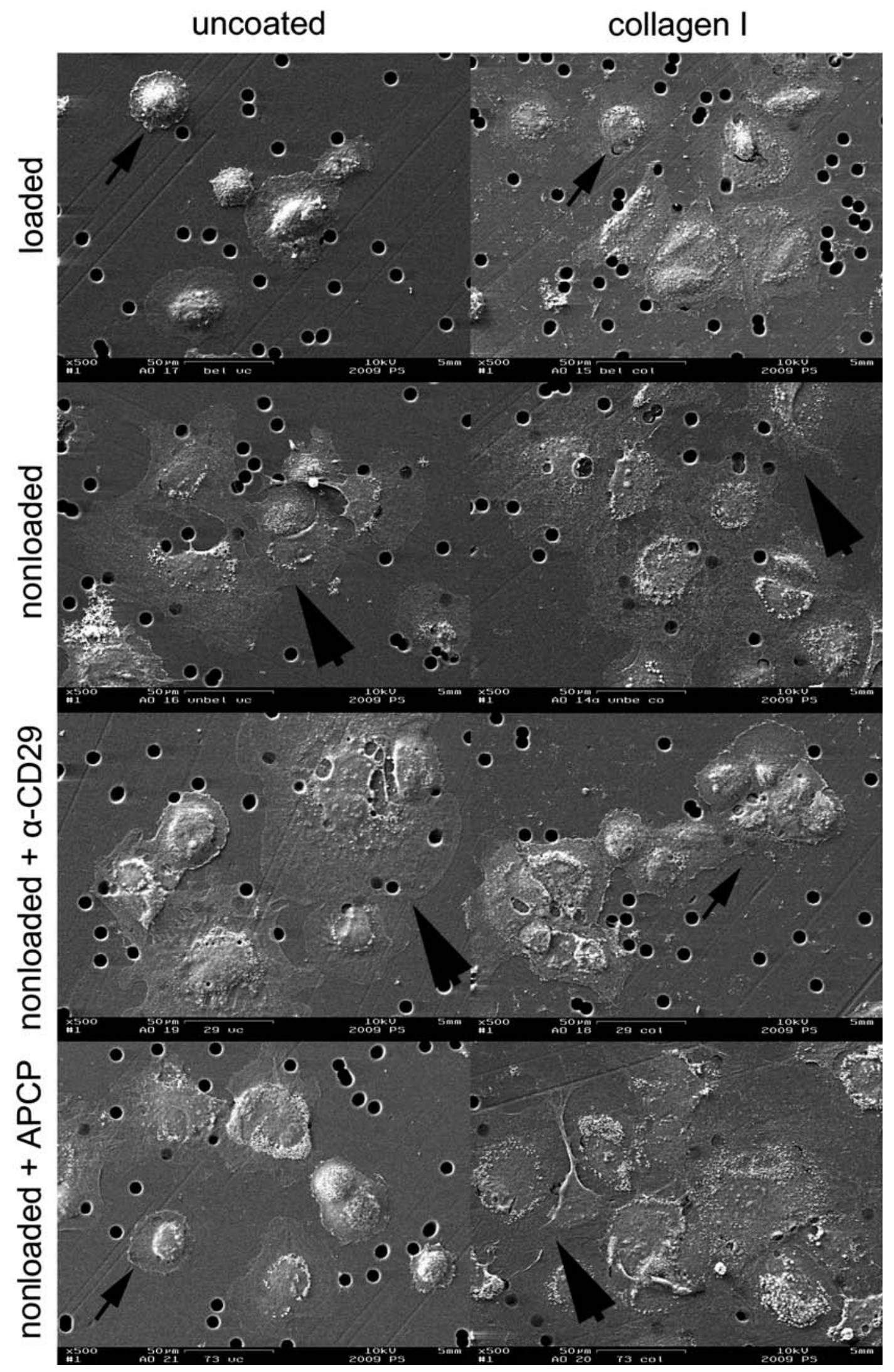

Fig. 5. Inhibition of CD29 and CD73 leads to reduced cell spreading of MSCs on collagen type I and uncoated migration filters, respectively. The cell morphology was analysed by SEM. Note the differences in cell spreading in loaded, non-loaded and treated MSCs as indicated by the arrows. Abbreviation: APCP, adenosine 5 ' $-(\alpha, \beta$-methylene $)$ diphosphate; thin arrows indicate decreased cell spreading; thick arrows indicate increased cell spreading. 
uncoated
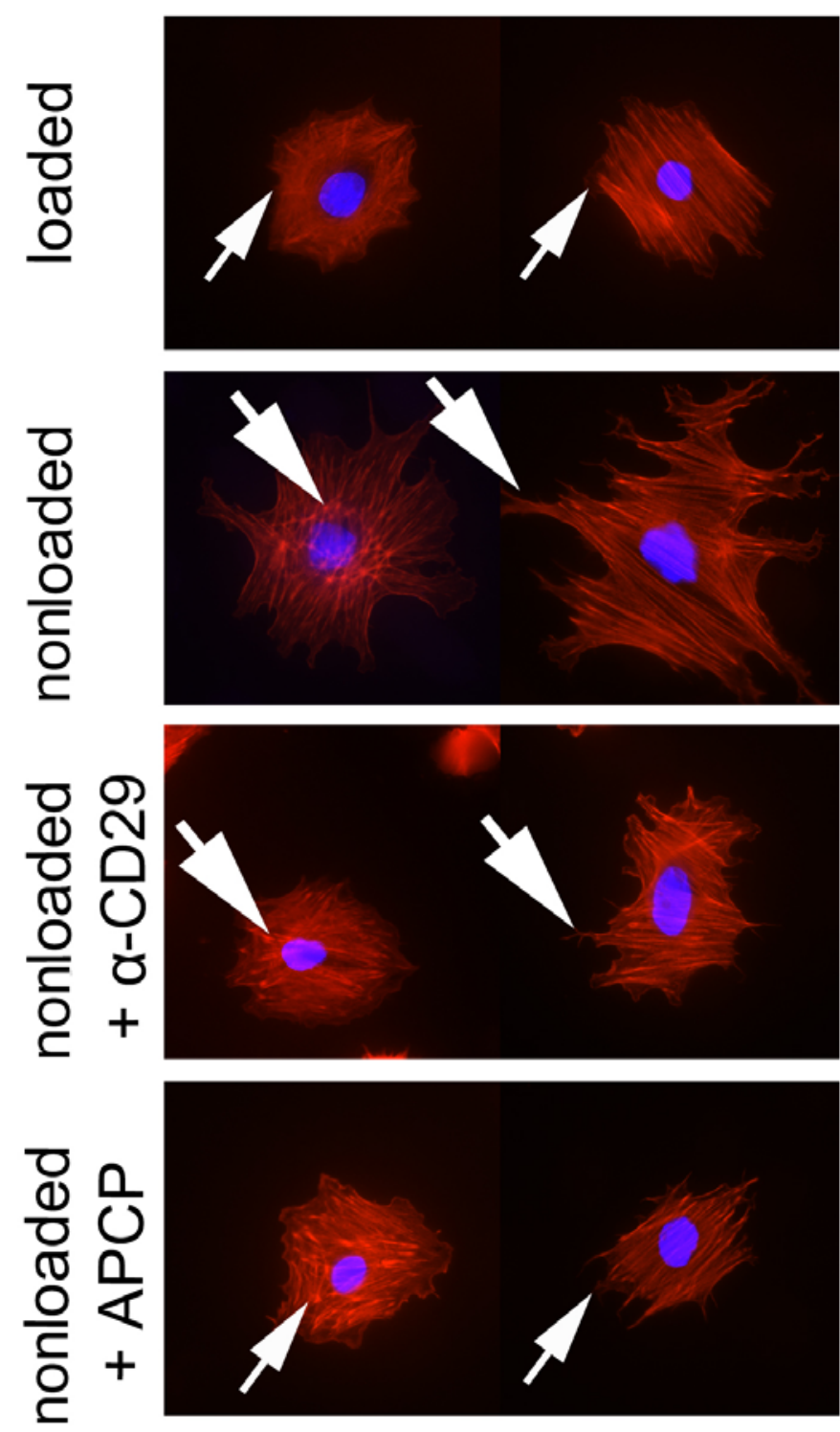

\section{collagen I}
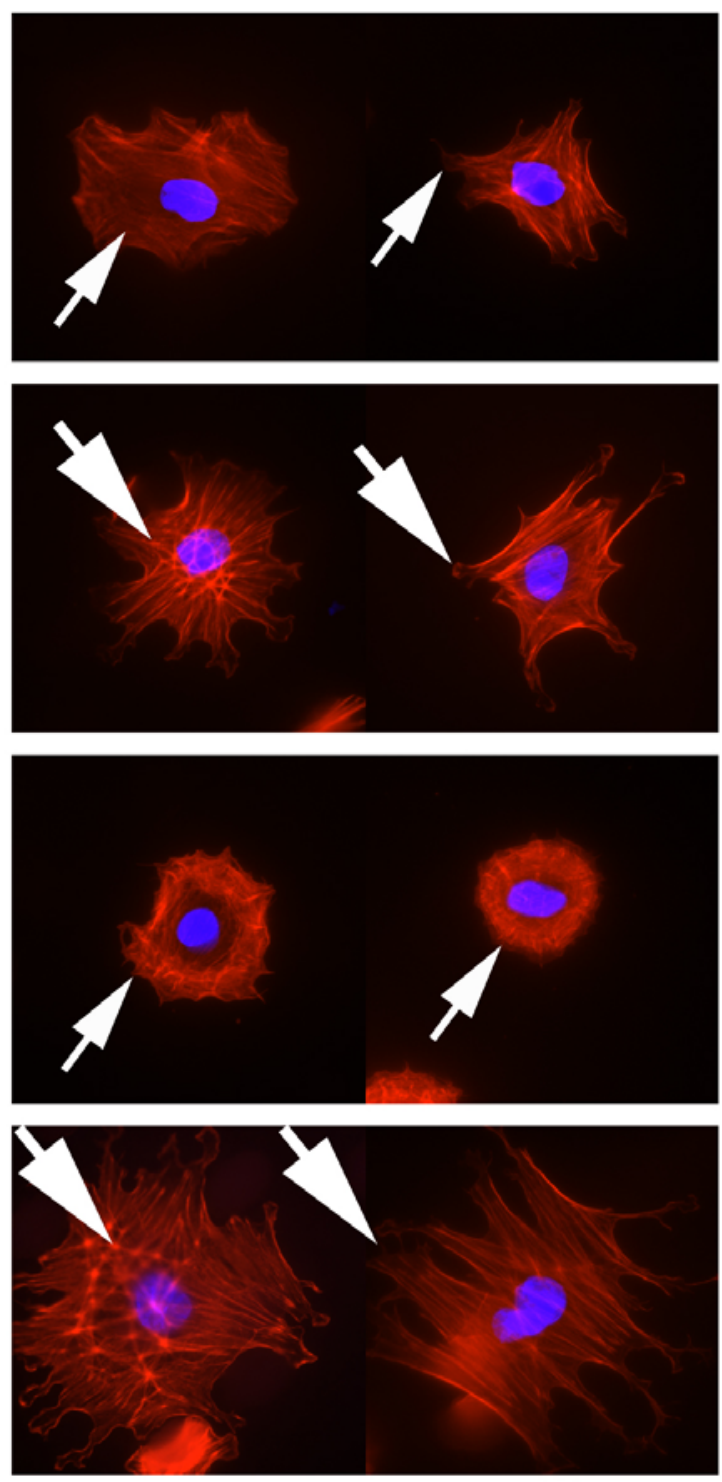

$50 \mu \mathrm{m}$

Fig. 6. Inhibition of CD29 and CD73 leads to changes in the cytoskeleton of MSCs on collagen type I and uncoated migration filters, respectively. The actin filaments and nuclei of migrated MSCs were stained with phalloidin dye-Alexa 594 and Hoechst-33258, respectively. Shown are representative pictures. Note the differences in lamellipodia (right pictures) and actin accumulation formation (left pictures) in loaded, non-loaded and nonloaded+treated MSCs as indicated by the arrows. Abbreviation: APCP, adenosine 5 ' $-(\alpha, \beta$-methylene $)$ diphosphate; thin arrows indicate decreased actin accumulation and lamellipodia formation; thick arrows indicate increased actin accumulation and lamellipodia formation.

control: ratio $_{\text {loaded }}=4.11$, ratio ${ }_{\text {non-loaded }}=5.17 ; p=0.001$; CD73 MFI normalised to the isotype control: ratio ${ }_{\text {loaded }}=$ 3.08 , ratio $_{\text {non-loaded }}=3.97 ; p=0.013$; Fig. 3D). On collagen type I, cell migration was significantly reduced in loaded MSCs (migrated cells per microscopic field: mean $_{\text {loaded, }}$ collagen type I $=53.4$ cells, mean $n_{\text {non-loaded, collagen type I }}=77.6$ cells, $p<0.05)$. On uncoated filters, a lower migration capacity for loaded MSCs was observed after Student's $t$ testing (migrated cells per microscopic field: mean $_{\text {loaded, uncoated }}=$ 44.3 cells, mean $_{\text {non-loaded, uncoated }}=65.2$ cells, $\left.p=0.049\right)$, but not when adjusted by Bonferroni's correction (Fig. 3E).

\section{Lower migration potential depends on CD73 and CD29}

Next, the putative involvement of CD73 and CD29 in the reduced migration capacity of loaded MSCs was analysed. On uncoated filters, blocking of CD73 by CD73 inhibitor adenosine 5 '-( $\alpha, \beta$-methylene) diphosphate (APCP) led to a statistically significant reduction in MSC migration compared to the control (migrated cells normalised to the non-loaded control: mean $_{\text {non-loaded, APCP, uncoated }}=83.0 \%, p<$ 0.05), whereas blocking of CD29 by anti-CD29 had no significant effect (Fig. 4A). However, the reduction of cell migration was less pronounced after CD73 inhibition than 


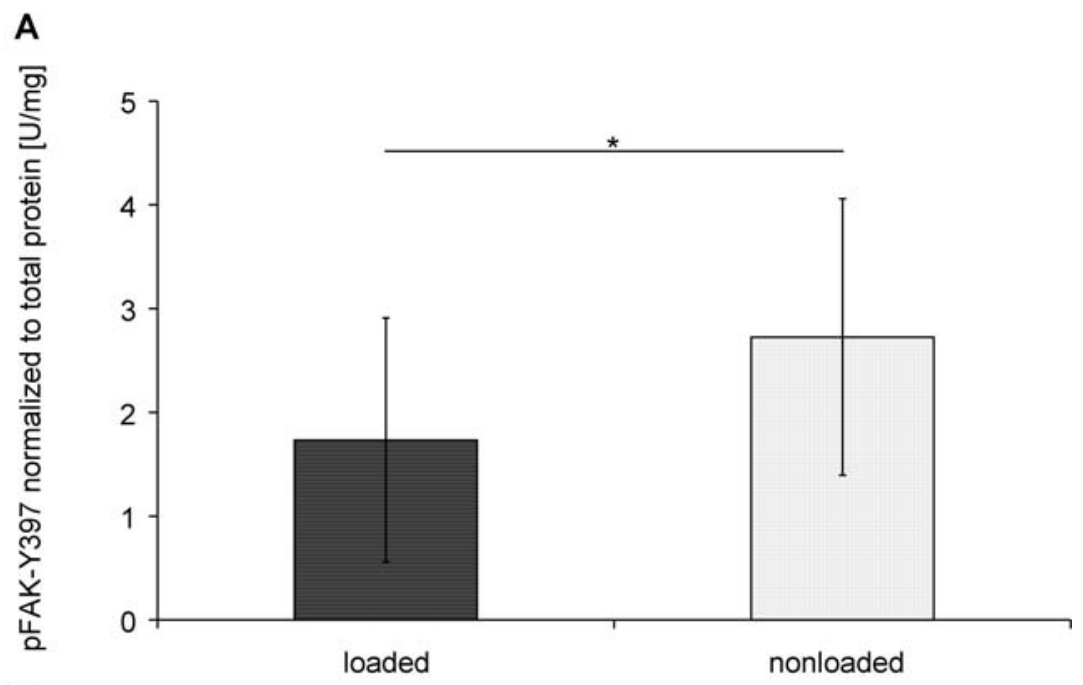

B

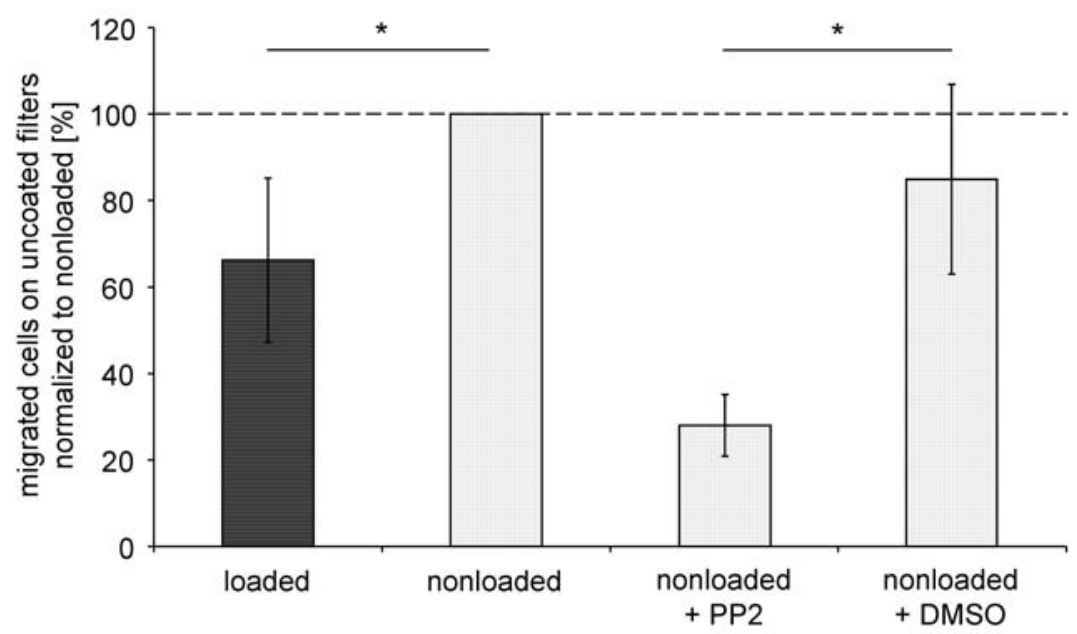

C

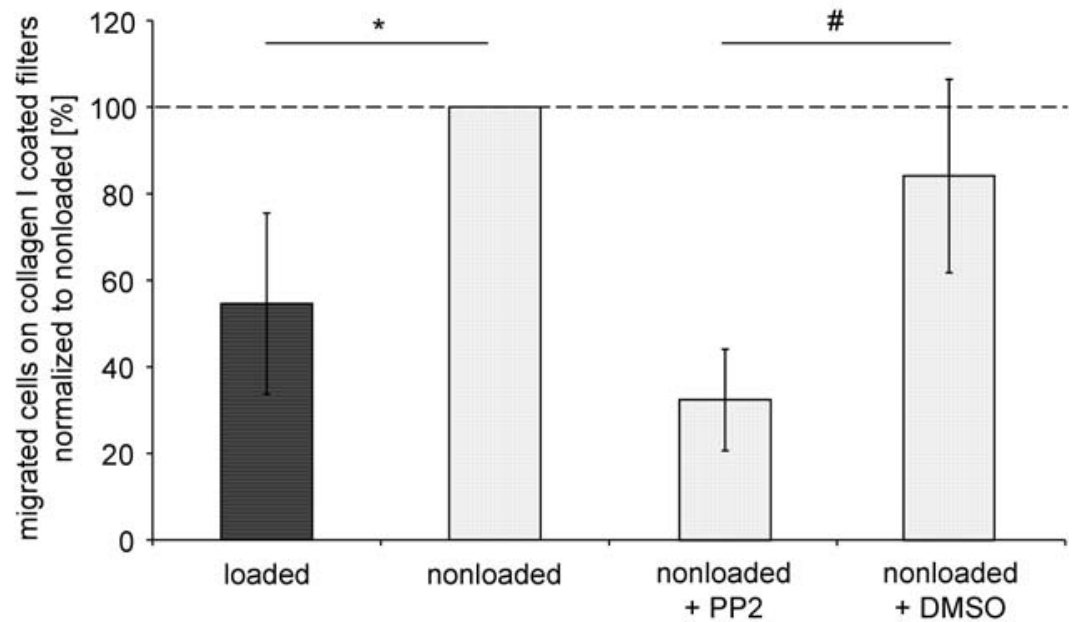

Fig. 7. FAK is hypo-phosphorylated in loaded compared to non-loaded MSCs and Src family kinases are essential for MSC migration. (A) The amount of pFAK (pTyr397) was measured with ELISA and normalised to total protein content. $(\mathbf{B}, \mathbf{C})$ Migration of loaded and non-loaded MSCs on $(\mathbf{B})$ uncoated and $(\mathbf{C})$ collagen I coated filters was investigated in the presence of $10 \mu \mathrm{M}$ SFK inhibitor PP2 (after five hours). Shown is the number of migrated cells after five hours normalised to non-loaded MSCs. Abbreviation: SFK, Src kinase family $(n=5, \#, p$ $=0.023$ without Bonferroni correction; ${ }^{*}, p<0.05$ ). 

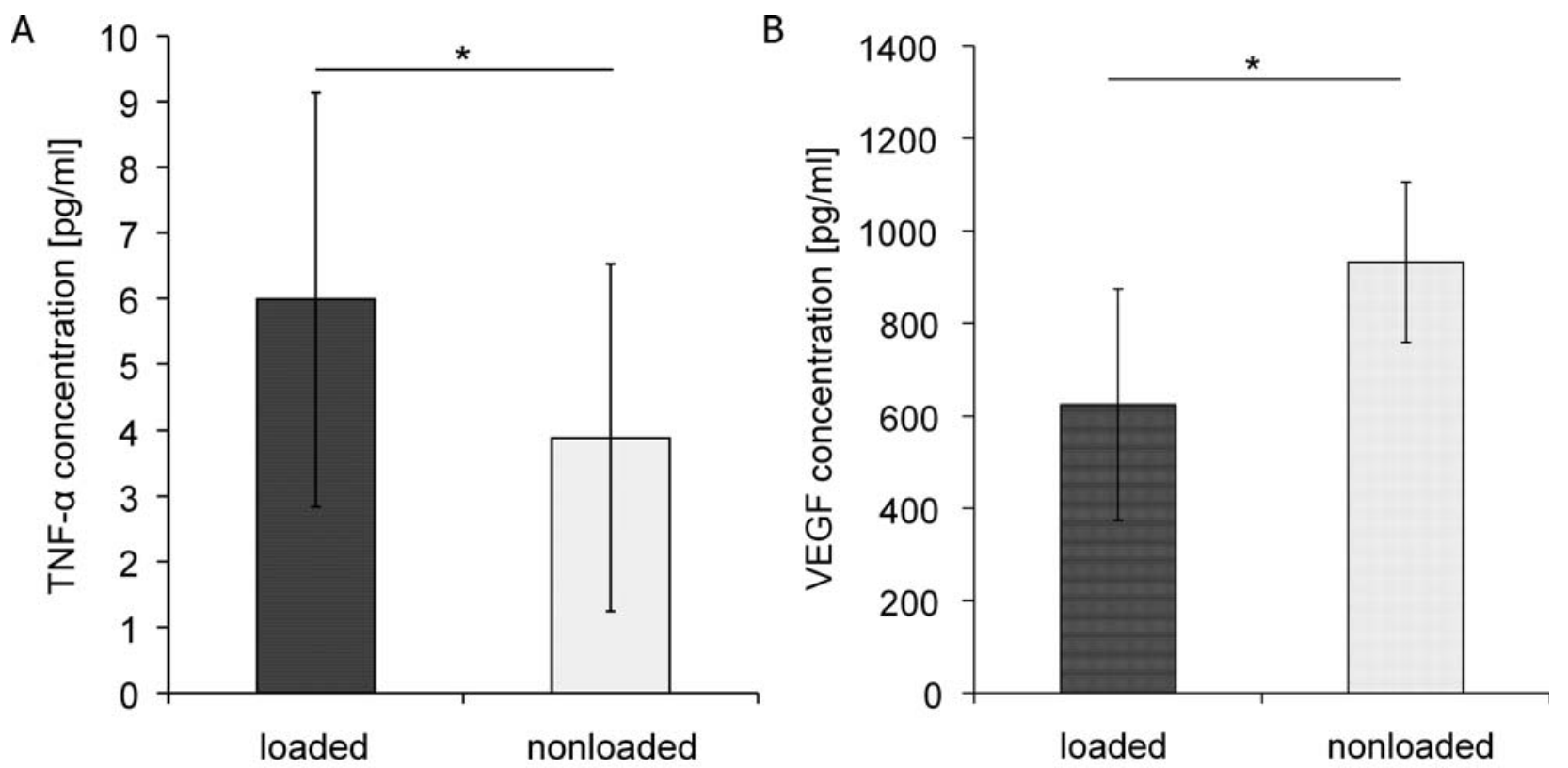

Fig. 8. Expression of TNF- $\alpha$ and VEGF, regulators of CD73, are altered after mechanical loading. ELISA of conditioned media of loaded and non-loaded MSCs were conducted. (A) TNF- $\alpha$, a potential negative regulator of CD73 is upregulated after mechanical loading. (B) VEGF, a potential positive regulator of CD29 is downregulated after mechanical loading (Kasper et al., 2010) $\left(n=5,{ }^{*}, p<0.05\right)$.

after mechanical loading. On collagen type I coated filters, blocking of CD29 led to a statistically significant reduction in MSC migration compared to the control after Student's $t$ testing (migrated cells normalised to the non-loaded control: mean $_{\text {non-loaded, anti-CD29, collagen type I }}=69.2 \%, p=0.05$ ), but not when adjusted by Bonferroni's correction, whereas blocking of CD73 by APCP had no significant effect (Fig. 4B). Simultaneous blocking of CD29 and CD73 - on both coatings - led to a statistically significant reduction of MSC migration compared to the control (migrated cells normalised to the non-loaded control: mean

APCP, uncoated $=82.5 \%, p<0.05 ;$ mean $_{\text {non-loaded, anti-CD29, APCP, collagen }}$
type I $=63 \%, p<0.05)$.

\section{Changes in the MSC cytoskeleton in response to mechanical loading and inhibition of CD73 and CD29}

Changes in the migratory behaviour of cells are closely associated with alterations in cell spreading and cytoskeleton organisation. To address this issue, SEM analysis of loaded and non-loaded MSCs with and without treatment with CD29- and CD73-inhibitors were conducted and revealed less cell spreading in loaded and inhibitor-treated cells compared to non-loaded cells (Fig. 5). Moreover, migration depends on cytoskeleton remodelling, which is also sensitive to mechanical stress. Thus, the cytoskeletal structure was further investigated. As depicted in Fig. 6, there are less actin accumulations and lamellipodia formation detectable in loaded MSCs compared to non-loaded ones. Non-loaded MSCs treated with the CD29 blocking antibody and APCP resembled the loaded phenotype on collagen type I, and uncoated filters, respectively. Thus, these data further support the finding that mechanical loading inhibits the migratory capacity of MSCs.

\section{Candidate downstream targets of CD73 and CD29 contribute to the mechanically induced decrease in MSC migration}

CD29 is known to activate FAK upon mechanical stimulation. Thus, the amount of pFAK (pTyr397) was measured and found to be reduced in loaded compared to non-loaded MSCs $\left(\right.$ mean $_{\text {loaded }}=1.73 \mathrm{U} / \mathrm{mg}$, mean non-loaded $=2.72 \mathrm{U} / \mathrm{mg}, p=0.035$; Fig. 7A). Once activated, FAK allows interaction with a number of Src family kinases (SFKs). Moreover, CD73 is known to signal through SFKs. Therefore, it was investigated whether SFKs are involved in MSC migration. On uncoated filters, SFK inhibition by PP2 resulted in a significant reduction of MSC migration (migrated cells normalised to the non-loaded control: mean non-loaded, PP2, uncoated $=28.0 \%$, mean $_{\text {non-loaded, DMSO, uncoated }}=90.4$
$\%, p<0.05)$. On collagen type I coated filters, a lower migration capacity for PP2 treated MSCs was observed after Student's $t$ testing (migrated cells normalised to the non-loaded control: mean ${ }_{\text {non-loaded, PP2, collagen type I }}=32.4 \%$, mean $\left._{\text {non-loaded, DMSO, collagen type I }}=108.6 \%, p=0.023\right)$ but not when adjusted by Bonferroni's correction (Fig. 7B,C).

\section{TNF- $\alpha$ and VEGF might regulate CD73 and CD29 expression, respectively}

A number of cytokines and growth factors are known to regulate CD73 and CD29 expression. To identify potential up-stream regulators of mechanoregulated CD73, the conditioned media (CM) of loaded and non-loaded cells were analysed. Among the investigated factors, the CD73 regulators Il-4 and INF- $\gamma$ were not detectable, whereas Il-1 $\beta$ was not regulated. In contrast, the CD73 regulator TNF- $\alpha$ was increased and the CD29 regulator VEGF was decreased in all three animals (Table 2). To statistically evaluate these data, ELISA analysis was performed with CM from MSCs from five animals (TNF- $\alpha$ concentration: 
Table 2: Multiplex analysis of conditioned media $[\mathrm{pg} / \mathrm{mL}]$

\begin{tabular}{|c|c|c|c|c|c|c|}
\hline & \multicolumn{3}{|c|}{ Loaded } & \multicolumn{3}{|c|}{ Non-loaded } \\
\hline & Rat 1 & Rat 2 & Rat 3 & Rat 1 & Rat 2 & Rat 3 \\
\hline ACTH & n.e. & n.e. & n.e. & n.e. & n.e. & n.e. \\
\hline RANKL & n.e. & n.e. & n.e. & n.e. & n.e. & n.e. \\
\hline Eotaxin & n.e. & n.e. & n.e. & n.e. & n.e. & n.e. \\
\hline GCSF & n.e. & n.e. & n.e. & n.e. & n.e. & n.e. \\
\hline GMCSF & n.e. & n.e. & n.e. & n.e. & n.e. & n.e. \\
\hline $\mathrm{GRO} / \mathrm{KC}$ & 5680 & 142 & 2115 & 569 & 55.05 & 6955 \\
\hline IFNg & n.e. & n.e. & n.e. & n.e. & n.e. & n.e. \\
\hline IL-10 & 150 & n.e. & n.e. & n.e. & n.e. & 67.8 \\
\hline IL-12p70 & n.e. & n.e. & n.e. & n.e. & n.e. & n.e. \\
\hline IL-13 & n.e. & n.e. & n.e. & n.e. & n.e. & n.e. \\
\hline IL-17 & 1.27 & 0.9235 & 1.0625 & 0.6485 & 0.958 & 0.9235 \\
\hline IL-18 & n.e. & n.e. & n.e. & n.e. & n.e. & n.e. \\
\hline IL-1a & 4.385 & n.e. & n.e. & 2.925 & n.e. & 2.31 \\
\hline IL-1b & n.e. & 6.34 & n.e. & n.e. & 2.945 & n.e. \\
\hline IL-2 & n.e. & 7.26 & n.e. & n.e. & n.e. & n.e. \\
\hline IL-4 & n.e. & n.e. & n.e. & n.e. & n.e. & n.e. \\
\hline IL-5 & 3.455 & n.e. & 2.165 & n.e. & n.e. & 4.98 \\
\hline IL-6 & 919 & 239 & 224 & 113 & 129.5 & 1765 \\
\hline IL-9 & n.e. & n.e. & n.e. & n.e. & n.e. & n.e. \\
\hline IP-10 & n.e. & n.e. & n.e. & n.e. & n.e. & n.e. \\
\hline MCP-1 & 1275 & 100.95 & 646 & 181 & 27.25 & 893 \\
\hline MIP-1a & 244.5 & 28.85 & 90.05 & 29.05 & n.e. & 203 \\
\hline RANTES & 845.5 & 65.6 & 652 & 385.5 & 31.65 & 701 \\
\hline TNFa* & 8.445 & 31.45 & 4.645 & n.e. & 12 & 4.125 \\
\hline VEGF* & 1740 & 963.5 & 1645 & 2230 & 1475 & 2295 \\
\hline Leptin & 4.925 & n.e. & 4.715 & 4.24 & n.e. & 4.3 \\
\hline
\end{tabular}

$N=3$

Abbreviation: n.e. not expressed

* - concurrently regulated in all three animals

mean $_{\text {loaded }}=6.0 \mathrm{pg} / \mathrm{mL}$, mean $_{\text {non-loaded }}=3.9 \mathrm{pg} / \mathrm{mL} ; p=$ 0.003; Figure 8; VEGF concentration: mean $_{\text {loaded }}=623.5$ $\mathrm{pg} / \mathrm{mL}$, mean $_{\text {non-loaded }}=931.8 \mathrm{pg} / \mathrm{mL} ; p=0.029$ (Kasper et al., 2010)).

\section{Discussion}

Interfragmentary movement - especially compression is essential for successful fracture repair (Goodship and Kenwright, 1985). Hence, in the present study the influence of mechanical loading on the MSC characteristics and associated functions was investigated. Our results show a pivotal role for CD29 and CD73 in the migratory response of MSCs upon loading.

\section{Mechanoregulation of CD73 and CD29 in MSCs}

The results presented here demonstrate that mechanically loaded MSCs downregulate CD73 and CD29, but show molecular and phenotypic characteristics of MSCs (Dominici et al., 2006). Our data are in contrast to previous studies reporting an upregulation of CD29 expression in other cell types of mesenchymal origin, namely chondrocytes and myoblasts. The response of those cells was studied under cyclic hydrostatic pressure and tension, respectively (Lucchinetti et al., 2004; Fan et al., 2009). This discrepancy is likely due to not only their differentiated stage but also the different biomechanical loading regimes, since a strain specific regulation seems to be more the rule (Wong et al., 2003). This is especially important, since most former expression analyses of CD29 in mesenchymal cells were not conducted using compression. Mechanoregulation of CD73 and CD29 might be mediated by TNF- $\alpha$ (Kalsi et al., 2002; Hunsucker et al., 2005) and VEGF (Lee et al., 2006), respectively. Extracellular VEGF concentration is decreased in response to mechanical loading, possibly leading to reduced CD29 expression (Kasper et al., 2010). In contrast, TNF- $\alpha$ expression was mechanically upregulated, potentially negatively regulating CD73 expression. The downregulation of CD73 and CD29 was observed on a transcription and protein level. This data corroborates that CD73 activity correlates with mRNA levels in most murine tissues and human cell lines (reviewed in Hunsucker et al., 2005). However, also a direct regulation via mechanoresponsive promoter elements could be possible (Hansen et al., 1995). Moreover, hypoxia is a major regulator of both CD73 and CD29 expression, possibly due to a HIF- $1 \alpha$ responsive 
element in their promoter region (Thompson et al., 2004; Keely et al., 2009). However, this pathway seems to be unlikely in the present setting, since in a similar study using human MSCs, direct oxygen measurement confirmed non-hypoxic conditions and HIF-1 $\alpha$ expression levels were unaffected by mechanical loading of MSCs (Kasper et al., 2007a).

\section{Mechanoregulation of MSC migration}

Here, we demonstrate for the first time that MSCs reduce their random migratory capacity, i.e., their basic motility machinery, after experiencing compressive loading and that this effect is mediated by CD73 and CD29. Cyclic strain has previously been shown to decrease cell migration of alveolar epithelial cells (Desai et al., 2008) and gastric mucosal cells (Osada et al., 1999), but to increase that of smooth muscle cells (Li et al., 2003) and osteoblasts (Bhatt et al., 2007), suggesting a cell-specific response. Direct comparison of these and our results is, however, difficult. So far, a concurrent investigation of mechanical loading and cell migration was analysed only under 2D conditions (e.g., wound scratch assay under the influence of cyclic strain applied with the Flexcell ${ }^{\mathbb{R}}$ systems). However, it is known that cell function and gene/protein expression may be altered substantially by a $2 \mathrm{D}$ monolayer culture as opposed to a 3D culture (Lee et al., 2007; Hong and Stegemann, 2008). Because of this fact and the greater physiological relevance, in this study, mechanical loading was carried out under 3D conditions. Unfortunately, there is no method available to date to mechanically stimulate and measure cell migration concurrently in a $3 \mathrm{D}$ environment. Therefore, to evaluate MSC migration, the cells were removed from the $3 \mathrm{D}$ culture, potentially introducing a bias in interpretation of the results.

The process of cell migration can be viewed as a fivestep cycle, which involves cell polarisation, extension of a protrusion, formation of stable adhesion near the leading edge of the protrusion, translocation of the cell body forward and release of adhesion and retraction at the cell rear. Integrins belong to a major family of promigratory receptors. They support adhesion to the ECM, stabilise the protrusion by means of structural connections to the cytoskeleton, and activate migration-related signalling molecules (Ridley et al., 2003; Wang et al., 2008). The involvement of CD29 in MSC migration has been demonstrated in vivo: e.g. lower numbers of MSCs engrafted and migrated into ischemic myocardium, if pretreated with neutralising antibodies against CD29 (Ip et al., 2007). An involvement of CD73 in cell migration was already suggested for other cell types. However, its role in cell migration is less clear. For example, CD73 expression is related to metastatic potential in human breast cancer cell lines (Zhou et al., 2007). CD73 over expression increased migration of T-47D and of MB-MDA-231 in vitro, whereas APCP decreased both (Wang et al., 2008). In this study, the inhibitory effect of APCP and a CD29-blocking antibody on MSC migration was observed only on uncoated and collagen type I coated filters, respectively. These data corroborate that $\mathrm{CD} 73$ possibly acts as an adhesion molecule for extracellular matrix components such as laminin and fibronectin (Zimmermann, 1992), which are likely to be present on uncoated filters in culture medium containing serum proteins, but not collagen (Stochaj et al., 1989). Another explanation could be that CD29 possibly dimerises favourably to the integrins $\alpha 1 \beta 1$ and $\alpha 2 \beta 1$. These integrins are the major collagen receptors whereas integrins $\alpha 5 \beta 1$ and $\alpha 6 \beta 1$ are the major fibronectin and laminin receptors (Chamberlain et al., 2007). However, the treatment of MSCs with APCP did not reduce the migration capacity to the same degree, as did mechanical loading. A possible explanation could be that further adhesion molecules, chemokines, cytokines, proteases or growth factors receptor tyrosine kinases involved in cell migration might be affected by mechanical loading, such as CXCL8, CCR3, or CXCR4, and the growth factors receptor tyrosine kinases for HGF, IGF and PDGF (Ponte et al., 2007).

Thus, CD73 and CD29 mediate the mechanically induced migration behaviour of MSCs depending on the underlying extracellular matrix, but further studies will need to identify potential additional players (Paulick and Bertozzi, 2008).

\section{Mechanoregulation of FAK in MSCs}

In our study, the CD29 downstream target FAK-Y397 was reduced after three days of mechanical loading of MSCs. In short term mechanical stimulation experiments, however, cyclic strain ( $1 \%$ elongation, 15 cycles/min and $4 \mathrm{~h}$ ) caused increased phosphorylation of FAK-Y397 in osteoblastic MC3T3 cells and primary osteoblastic cells (Boutahar et al., 2004). In another study, compressive stimulation (17.8N compressive load, $1 \mathrm{~Hz}, 30 \mathrm{~min}$ ) of bone revealed a rapid load-induced activation of FAK-Y397 (Moalli et al., 2001). One explanation for this discrepancy could be a proposed biphasic effect of FAK phosphorylation as suggested recently (Desai et al., 2009); these authors observed that FAK-Y397 levels are transiently elevated after $30 \mathrm{~min}$ of cyclic strain, but significantly decrease by $6 \mathrm{~h}$ compared to unstimulated controls. Thus, they concluded that FAK phosphorylation increases over short time intervals of mechanical stimulation, but decreases after enhanced loading periods, which is further confirmed by our observations (Desai et al., 2009). A second explanation could be a substrate specific regulation of FAK phosphorylation; e.g., in MSCs stimulated by cyclic strain, FAK-Y397 was increased on laminin and decreased on fibronectin coating (Huang et al., 2009). However, fibrin has not been investigated thus far. Importantly, a direct CD29-FAK association was proposed based on results of in vitro peptide binding studies (Schaller et al., 1995). Moreover, ablation of CD29 expression suppresses FAK-Y397 in mammary tumour cells (White et al., 2004). Therefore, although we cannot rule out contrary short term effects, for long term mechanical stimulation, the reduced expression of CD29 is likely to cause the decrease of FAK-Y397.

\section{Actin cytoskeleton turnover in loaded MSCs}

In this study, during migration, the formation of lamellipodia and actin accumulation and cell spreading were suppressed after mechanical loading, the first observation being in accordance with another study (Osada et al., 1999). A similar phenotype was observed after inhibition of CD73 
and CD29 in MSCs. A possible regulator involved in CD29-mediated cell migration is the FAK-Src family kinase (SFK)-complex (Sieg et al., 1999). FAK-SFK signalling induces lamellipodia extensions and membrane protrusion and promotes focal adhesion turnover (Guo and Giancotti, 2004; Mitra et al., 2005). Mutation of FAK-Y397 impairs the ability of FAK to promote cell spreading (Owen et al., 1999). Cell migration in fibroblasts is decreased by SFK inhibition, which was also observed in MSCs in this study (Sieg et al., 1999). Importantly, our data indicate that CD73 also links to the cytoskeleton. Indeed, it has been shown that filamentous actin accumulates under clusters of glycosylphosphatidylinositol (GPI)-anchored proteins (e.g., CD73) induced by receptor ligation and cross-linking (Harder and Simons, 1999; Paulick and Bertozzi, 2008). How GPI-anchored proteins, lacking an intracellular domain, transduce signals across the membrane remains puzzling. It has been hypothesised to occur by close association with transmembrane signalling molecules in lipid rafts (Paulick and Bertozzi, 2008). For example, antibody-mediated triggering of lymphocyte CD73 induces tyrosine phosphorylation of a $\sim 26 \mathrm{kDa}, \sim 28$ $\mathrm{kDa}$ and $\sim 50 \mathrm{kDa}$ protein (Airas et al., 1997). Furthermore, human and murine lymphocyte CD73 signalling seems to depend on Lck- and Fyn, two members of the SFK family and involved in cell migration, respectively (Löwenberg et al., 2006; Resta et al., 1994; Yamashita et al., 1998). Thus, we conclude that the reduced migratory capacity of mechanically stimulated MSCs, associated with less formation of lamellipodia extensions and membrane protrusion, via downregulation of CD73 and CD29 might be due to impaired SFK and FAK-SFK signalling, respectively. Furthermore, a connection between the integrin $\beta 2$-subgroup LFA-1 and CD73 has been suggested (Airas et al., 2000) and CD29-mediated cell adhesion was recently shown to be regulated by another GPI-linked cell surface protein, the urokinase receptor (Airas et al., 1997). Thus, in future studies, it will be interesting to investigate a potential crosstalk between the two mechanoregulated cell surface proteins CD73 and CD29.

In summary, mechanical loading of MSCs leads to decreased expression of CD73 and CD29, possibly via altered expression of TNF- $\alpha$ and VEGF, reduced activation of FAK and, potentially SFKs, less actin accumulations and lamellipodia formation and thereby reduced migration.

\section{Conclusion}

Data from this study provide evidence that migration of MSCs is strongly influenced by mechanical stimulation equivalent to conditions of the early bone-healing phase. We therefore speculate that MSCs migrate into the early fracture haematoma, become entrapped by mechanical stimulation, and thereby accumulate in the haematoma in order to fulfil their biological role to contribute to bone regeneration. Future studies will need to investigate the concurrent influence of mechanical loading and inflammatory chemokines/cytokines (chemotaxis) and/ or biomechanical properties of the underlying ECM (durotaxis) on MSC migration in vitro.

\section{Acknowledgements}

This study was supported partly by the Federal Ministry of Education and Research (BMBF) excellence cluster, Berlin-Brandenburg Centre for Regenerative Therapies, and partly by the German Research Foundation (DFG SFB 760; BSRT fellowship to J. Kopf). The authors would like to thank Prof. Petra Knaus at the Institute for Chemistry and Biochemistry, Freie Universität Berlin and Dr. Bettina Willie for fruitful discussions and critical reading of the manuscript. We are grateful to J.-E. Hoffmann for kindly providing the bioreactor graphic and $\mathrm{M}$. Textor and the staff of the Medical-Technical Laboratories (Charité) for excellent technical support.

\section{References}

Airas L, Niemelä J, Salmi M, Puurunen T, Smith DJ, Jalkanen S (1997) Differential regulation and function of CD73, a glycosyl-phosphatidylinositol-linked 70-kD adhesion molecule, on lymphocytes and endothelial Cells. J Cell Biol 136: 421-431.

Airas L, Niemela J, Jalkanen S (2000) CD73 Engagement promotes lymphocyte binding to endothelial cells via a lymphocyte function-associated antigen-1dependent mechanism. J Immunol 165: 5411-5417.

Barker TH, Hagood JS (2009) Getting a grip on Thy-1 signaling. Biochim Biophys Acta 1793: 921-923.

Bhatt KA, Chang EI, Warren SM, Lin S, Bastidas N, Ghali S, Thibboneir A, Capla JM, McCarthy JG, Gurtner GC (2007) Uniaxial mechanical strain: An in vitro correlate to distraction osteogenesis. J Surg Res 143: 329-336.

Boutahar N, Guignandon A, Vico L, Lafage-Proust M (2004) Mechanical strain on osteoblasts activates autophosphorylation of focal adhesion kinase and prolinerich tyrosine kinase 2 tyrosine sites involved in ERK activation. J Biol Chem 279: 30588-30599.

Chamberlain G, Fox J, Ashton B, Middleton J (2007) Concise review: Mesenchymal stem cells: Their phenotype, differentiation capacity, immunological features, and potential for homing. Stem Cells 25: 2739-2749.

Claes LE, Heigele CA, Neidlinger-Wilke C, Kaspar D, Seidl W, Margevicius KJ, Augat P (1998) Effects of mechanical factors on the fracture healing process. Clin Orthop Relat Res 355 Suppl: S132-147.

Desai LP, Chapman KE, Waters CM (2008) Mechanical stretch decreases migration of alveolar epithelial cells through mechanisms involving Rac1 and Tiam1. Am J Physiol Lung Cell Mol Physiol 295: L958-L965.

Desai LP, White SR, Waters CM (2009) Mechanical stretch decreases FAK phosphorylation and reduces cell migration through loss of JIP3-induced JNK phosphorylation in airway epithelial cells. Am J Physiol Lung Cell Mol Physiol 297: L520-L529.

Dobson KR, Reading L, Haberey M, Marine X, Scutt A (1999) Centrifugal isolation of bone marrow from bone: An improved method for the recovery and quantitation of bone marrow osteoprogenitor cells from rat tibiae and femora. Calcif Tissue Int 65: 411-413. 
Dominici M, Blanc KL, Mueller I, Slaper-Cortenbach I, Marini F, Krause D, Deans R, Keating A, Prockop D, Horwitz E (2006) Minimal criteria for defining multipotent mesenchymal stromal cells. The International Society for Cellular Therapy Position Statement. Cytotherapy 8: 315 317.

Duff SE, Li C, Garland JM, Kumar S (2003) CD105 is important for angiogenesis: evidence and potential applications. FASEB J 17: 984-992.

Eliceiri BP (2001) Integrin and growth factor receptor crosstalk. Circ Res 89: 1104-1110.

Falk W, Goodwin Jr. RH, Leonard EJ (1980) A 48well micro chemotaxis assembly for rapid and accurate measurement of leukocyte migration. J Immunol Methods 33: $239-247$.

Fan X, Zou R, Zhao Z, Yang P, Li Y, Song J (2009) Tensile strain induces integrin betal and ILK expression higher and faster in 3D cultured rat skeletal myoblasts than in 2D cultures. Tissue Cell 41: 266-270.

Friedl P (2004) Prespecification and plasticity: shifting mechanisms of cell migration. Curr Opin Cell Biol 16: 14-23.

Gardner TN, Evans M, Hardy J, Kenwright J (1997) Dynamic interfragmentary motion in fractures during routine patient activity. Clin Orthop Relat Res 336: 216 225.

Goodship AE (1992) Mechanical stimulus to bone. Ann Rheum Dis 51: 4-6.

Goodship A, Kenwright J (1985) The influence of induced micromovement upon the healing of experimental tibial fractures. J Bone Joint Surg Br 67B: 650-655.

Guo W, Giancotti FG (2004) Integrin signalling during tumour progression. Nat Rev Mol Cell Biol 5: 816-826.

Hansen KR, Resta R, Webb CF, Thompson LF (1995) Isolation and characterization of the promoter of the human 5'-nucleotidase (CD73)-encoding gene. Gene 167: 307-312.

Harder T, Simons K (1999) Clusters of glycolipid and glycosylphosphatidylinositol-anchored proteins in lymphoid cells: accumulation of actin regulated by local tyrosine phosphorylation. Eur J Immunol 29: 556-562.

Hong H, Stegemann JP (2008) 2D and 3D collagen and fibrin biopolymers promote specific ECM and integrin gene expression by vascular smooth muscle cells. J Biomater Sci Polym Ed 19: 1279-1293.

Huang C, Chen M, Young T, Jeng J, Chen Y (2009) Interactive effects of mechanical stretching and extracellular matrix proteins on initiating osteogenic differentiation of human mesenchymal stem cells. J Cell Biochem 108: 1263-1273.

Hunsucker SA, Mitchell BS, Spychala J (2005) The 5 '-nucleotidases as regulators of nucleotide and drug metabolism. Pharmacol Ther 107: 1-30.

Ip JE, Wu Y, Huang J, Zhang L, Pratt RE, Dzau VJ (2007) Mesenchymal stem cells use integrin betal not CXC chemokine receptor 4 for myocardial migration and engraftment. Mol Biol Cell 18: 2873-2882.

Kalsi K, Lawson C, Dominguez M, Taylor P, Yacoub MH, Smolenski RT (2002) Regulation of ecto-5'nucleotidase by TNF- $\alpha$ in human endothelial cells. Mol Cell Biochem 232: 113-119.
Kasper G, Dankert N, Tuischer J, Hoeft M, Gaber T, Glaeser JD, Zander D, Tschirschmann M, Thompson M, Matziolis G, Duda GN (2007a) Mesenchymal stem cells regulate angiogenesis according to their mechanical environment. Stem Cells 25: 903-910.

Kasper G, Glaeser JD, Geissler S, Ode A, Tuischer J, Matziolis G, Perka C, Duda GN (2007b) Matrix metalloprotease activity is an essential link between mechanical stimulus and mesenchymal stem cell behavior. Stem Cells 25: 1985-1994.

Kasper G, Ode A, Groothuis A, Glaeser J, Gaber T, Wilson CJ, Geissler S, Duda GN (2010) Validation of beta-actin used as endogenous control for gene expression analysis in mechanobiology studies: Amendments. Stem Cells 28: 633-634.

Keely S, Glover LE, MacManus CF, Campbell EL, Scully MM, Furuta GT, Colgan SP (2009) Selective induction of integrin $\beta 1$ by hypoxia-inducible factor: implications for wound healing. FASEB J 23: 1338-1346.

Klein P, Schell H, Streitparth F, Heller M, Kassi J, Kandziora F, Bragulla H, Haas NP, Duda GN (2003) The initial phase of fracture healing is specifically sensitive to mechanical conditions. J Orthop Res 21: 662-669.

Komatsu DE, Hadjiargyrou M (2004) Activation of the transcription factor HIF-1 and its target genes, VEGF, HO-1, iNOS, during fracture repair. Bone 34: 680-688.

Lee T, Seng S, Li H, Kennel SJ, Avraham HK, Avraham S (2006) Integrin regulation by vascular endothelial growth factor in human brain microvascular endothelial cells: role of alpha6beta1 integrin in angiogenesis. J Biol Chem 281: 40450-40460.

Li C, Wernig F, Leitges M, Hu Y, Xu Q (2003) Mechanical stress-activated $\mathrm{PKC} \delta$ regulates smooth muscle cell migration. FASEB J 17: 2106-2108.

Löwenberg M, Verhaar AP, Bilderbeek J, Marle JV, Buttgereit F, Peppelenbosch MP, van Deventer SJ, Hommes DW (2006) Glucocorticoids cause rapid dissociation of a T-cell-receptor-associated protein complex containing LCK and FYN. EMBO Rep 7: 1023-1029.

Lucchinetti E, Bhargava M, Torzilli P (2004) The effect of mechanical load on integrin subunits a5 and $\beta 1$ in chondrocytes from mature and immature cartilage explants. Cell Tissue Res 315: 385-391.

Matziolis G, Tuischer J, Kasper G, Thompson M, Bartmeyer B, Krocker D, Perka C, Duda G (2006) Simulation of cell differentiation in fracture healing: mechanically loaded composite scaffolds in a novel bioreactor system. Tissue Eng 12: 201-208.

Mitra SK, Hanson DA, Schlaepfer DD (2005) Focal adhesion kinase: in command and control of cell motility. Nat Rev Mol Cell Biol 6: 56-68.

Moalli MR, Wang S, Caldwell NJ, Patil PV, Maynard CR (2001) Mechanical stimulation induces pp125FAK and pp60src activity in an in vivo model of trabecular bone formation. J Appl Physiol 91: 912-918.

Osada T, Watanabe S, Tanaka H, Hirose M, Miyazaki A, Sato N (1999) Effect of mechanical strain on gastric cellular migration and proliferation during mucosal healing: role of Rho dependent and Rac dependent cytoskeletal reorganisation. Gut 45: 508-515. 
Owen JD, Ruest PJ, Fry DW, Hanks SK (1999) Induced focal adhesion kinase (FAK) expression in FAK-null cells enhances cell spreading and migration requiring both auto- and activation loop phosphorylation sites and inhibits adhesion-dependent tyrosine phosphorylation of pyk2. Mol Cell Biol 19: 4806-4818.

Ozaki Y, Nishimura M, Sekiya K, Suehiro F, Kanawa M, Nikawa H, Hamada T, Kato Y (2007) Comprehensive analysis of chemotactic factors for bone marrow mesenchymal stem cells. Stem Cells Dev 16: 119-129.

Paulick MG, Bertozzi CR (2008) The glycosylphosphatidylinositol anchor: A complex membrane-anchoring structure for proteins. Biochemistry 47: 6991-7000.

Pfaffl MW, Horgan GW, Dempfle L (2002) Relative expression software tool (REST) for group-wise comparison and statistical analysis of relative expression results in real-time PCR. Nucleic Acids Res 30: e36.

Phillips A (2005) Overview of the fracture healing cascade. Injury 36: S5-S7.

Ponte AL, Marais E, Gallay N, Langonné A, Delorme B, Hérault O, Charbord P, Domenech J (2007) The in vitro mgration capacity of human bone marrow mesenchymal stem cells: Comparison of chemokine and growth factor chemotactic activities. Stem Cells 25: 1737-1745.

Resta R, Hooker S, Laurent A, Shuck J, Misumi Y, Ikehara Y, Koretzky G, Thompson L (1994) Glycosyl phosphatidylinositol membrane anchor is not required for $\mathrm{T}$ cell activation through CD73. J Immunol 153: 1046-1053.

Ridley AJ, Schwartz MA, Burridge K, Firtel RA, Ginsberg MH, Borisy G, Parsons JT, Horwitz AR (2003) Cell migration: Integrating signals from front to back. Science 302: 1704 -1709.

Rossert J, de Crombrugghe B (2002) Type I collagen: Structure, synthesis, and regulation. In: Principles of Bone Biology (Second Edition). Academic Press, San Diego. pp 189-210.

Rüster B, Grace B, Seitz O, Seifried E, Henschler R (2005) Induction and detection of human mesenchymal stem cell migration in the 48-well reusable Transwell assay. Stem Cells Dev 14: 231-235.

Schaller MD, Otey CA, Hildebrand JD, Parsons JT (1995) Focal adhesion kinase and paxillin bind to peptides mimicking beta integrin cytoplasmic domains. J Cell Biol 130: 1181-1187.

Sekiya I, Vuoristo JT, Larson BL, Prockop DJ (2002) In vitro cartilage formation by human adult stem cells from bone marrow stroma defines the sequence of cellular and molecular events during chondrogenesis. Proc Natl Acad Sci USA 99: 4397-4402.

Sieg D, Hauck C, Schlaepfer D (1999) Required role of focal adhesion kinase (FAK) for integrin-stimulated cell migration. J Cell Sci 112: 2677-2691.

Stochaj U, Dieckhoff J, Mollenhauer J, Cramer M, Mannherz HG (1989) Evidence for the direct interaction of chicken gizzard 5'-nucleotidase with laminin and fibronectin. Biochim Biophys Acta 992: 385-392.

Thibault MM, Hoemann CD, Buschmann MD (2007) Fibronectin, vitronectin, and collagen I induce chemotaxis and haptotaxis of human and rabbit mesenchymal stem cells in a standardized transmembrane assay. Stem Cells Dev 16: 489-502.

Thompson LF, Eltzschig HK, Ibla JC, Van De Wiele CJ, Resta R, Morote-Garcia JC, Colgan SP (2004) Crucial role for ecto-5' -nucleotidase (CD73) in vascular leakage during hypoxia. J Exp Med 200: 1395-1405.

Wang J, Thampatty BP (2008) Chapter 7: Mechanobiology of adult and stem cells. Int Rev Cell Mol Biol 271: 301-346.

Wang L, Zhou X, Zhou T, Ma D, Chen S, Zhi X, Yin L, Shao Z, Ou Z, Zhou P (2008) Ecto-5'-nucleotidase promotes invasion, migration and adhesion of human breast cancer cells. J Cancer Res Clin Oncol 134: 365-372.

White DE, Kurpios NA, Zuo D, Hassell JA, Blaess S, Mueller U, Muller WJ (2004) Targeted disruption of beta1-integrin in a transgenic mouse model of human breast cancer reveals an essential role in mammary tumor induction. Cancer Cell 6: 159-170.

Wong M, Siegrist M, Goodwin K (2003) Cyclic tensile strain and cyclic hydrostatic pressure differentially regulate expression of hypertrophic markers in primary chondrocytes. Bone 33: 685-693.

Yamashita Y, Hooker SW, Jiang H, Laurent AB, Resta R, Khare K, Coe A, Kincade PW, Thompson LF (1998) CD73 expression and fyn-dependent signaling on murine lymphocytes. Eur J Immunol 28: 2981-2990.

Zhou X, Zhi X, Zhou P, Chen S, Zhao F, Shao Z, Ou Z, Yin L (2007) Effects of ecto-5'-nucleotidase on human breast cancer cell growth in vitro and in vivo. Oncol Rep 17: 1341-1346.

Zhu H, Mitsuhashi N, Klein A, Barsky LW, Weinberg K, Barr ML, Demetriou A, Wu GD (2006) The role of the hyaluronan receptor CD44 in mesenchymal stem cell migration in the extracellular matrix. Stem Cells 24: 928935.

Zimmermann H (1992) 5'-Nucleotidase: molecular structure and functional aspects. Biochem J 285: 345-365.

\section{Discussion with Reviewers}

Reviewer I: I would recommend the inclusion of FACS histograms in Fig. 3 to provide a more clear view of difference in surface marker expression.

Authors: A reduction of protein expression and thereby a reduction of fluorescence intensity by e.g., $40 \%$ does not result in an extreme shift of the histogram, but is still biologically relevant. To clearly illustrate the difference between loaded and non-loaded MSCs, we therefore chose to display our data in bar charts and further validated our results on mRNA level. From our point of view, histograms, showing the differences less clear, will not add much value to the manuscript and were therefore not included.

Reviewer I: Please comment on the expression of VEGF and TNF- $\alpha$ and the role in the described result of the minor down regulation of the two surface markers. Especially the absolute amount of TNF- $\alpha$ is very low and there are only minor differences in the expression. Why do the authors check the effect of TNF- $\alpha$ in a more than 100 fold over 
dosage. What is the functional link between VEGF /TNF- $\alpha$ and the observed results of decreased migratory capacity? Authors: In this study the results demonstrated a reduced expression of MSC surface markers CD73 (ecto-5'nucleotidase) and CD29 (integrin $\beta 1$ ) after mechanical loading by $57 \%$ and $38 \%$, respectively. A downregulation of proteins within this range was proven by different studies to be biologically relevant. For example, an upregulation of the matrix metalloprotease-2 (MMP-2) in MSCs by 40-50 $\%$ led to a paracrine stimulation of angiogenesis, which was hindered by inhibition of MMP-2 in the presence of recombinant TIMP-2 (biological MMP-2 antagonist) and a pro-MMP-2 blocking antibody (a-pro-MMP-2) (Kasper et al., 2007; Glaeser et al., 2010, text references). Thus, we believe that the downregulation of the two surface markers in our study is also biologically relevant.

A number of cytokines and growth factors are known to regulate CD73 and CD29 expression, e.g. TNF- $\alpha$ and VEGF (Kalsi et al., 2002; Hunsucker et al., 2005; Lee et al., 2006, text references). It is important to note that the expression of TNF- $\alpha$ (a CD73 negative regulator (Kalsi et al., 2002; Hunsucker et al., 2005)) and the expression of VEGF (a CD29 positive regulator (Lee et al., 2006)) were increased by $54 \%$ and decreased by $33 \%$, respectively. Thus, the range of alteration is comparable to the change of expression of the cell surface markers after loading. Therefore, we hypothesise that the mechanically induced decrease of the migratory capacity of MSCs via CD73 and CD29 occurs possibly via altered expression of TNF- $\alpha$ and VEGF.

In order to get a first idea whether TNF- $\alpha$ indeed influences the expression of CD73, we simplified the experimental set-up and treated 2D-cultured MSCs with high dose of TNF- $\alpha$ and found the expression of CD73 mRNA to be downregulated (preliminary data not included in the manuscript). However, to fully reveal this mechanism in 3D and after loading, extensive analyses (dose- and time-dependent; protein- and mRNA-level) are needed which, we believe, is beyond the scope of this study and will therefore be part of future studies.

Furthermore, the set of marker molecules defined to be expressed on MSC is more or less described for in vitro cultivated cells. The set of in vivo markers for MSCs is object of intense discussion (Augello et al., 2010, additional reference). Since marker molecule expression can differ in the in vivo and the in vitro situation, and isolated MSCs will probably change the set of surface proteins upon in vitro cultivation, it is questionable if the observed results can be translated in the in vivo situation.

Augello et al. (2010) hypothesise in their review that the possibility exists that the MSC phenotype varies between in vitro and in vivo mainly because of the removal from their natural environment and the use of artificial culture conditions. This hypothesis is based on publications by Jones et al. (2002, 2006) (additional references) that describe MSCs loosing the expression of some surface markers (Stro-1, LNGFR, and HLA-DR) while also acquiring new ones (CD106, CD146) during in vitro cultivation. However, it is important to note that neither CD73 nor CD29 were shown to change during in vitro cultivation in these studies. In fact, Jones et al. (2006) provided evidence that the expression level of CD73 remained the same between freshly isolated and culture-expanded MSCs. Moreover, CD29 is the "cluster of differentiation" for integrin $\beta 1$. MSCs express several integrins, such as $\alpha 1 \beta 1, \alpha 2 \beta 1, \alpha 3 \beta 1, \alpha 4 \beta 1, \alpha 5 \beta 1, \alpha 6 \beta 1$, $\alpha 6 \beta 4 \alpha \mathrm{V} \beta 3$ and $\alpha \mathrm{V} \beta 5$ with different ligand binding properties, suggesting a key functional role for integrin $\beta 1$ (CD29) in MSCs (Ode et al., 2010, additional reference). In addition, the involvement of CD29 in MSC migration has been demonstrated in vivo: e.g., lower numbers of MSCs engrafted and migrated into ischemic myocardium, if pre-treated with neutralising antibodies against CD29 (Ip et al., 2007, text reference). Thus, it is very unlikely that this key cell surface protein will be absent in vivo.

In summary, these data indicate that the cell surface proteins CD73 and CD29 are not in vitro artefacts. Therefore, it is reasonable that the observed results could be translated in the in vivo situation. However, we totally agree that conclusive evidence needs to be obtained from appropriate in vivo studies.

\section{Additional References}

Augello A, Kurth TB, De Bari C. (2010) Mesenchymal stem cells: a perspective from in vitro cultures to in vivo migration and niches. Eur Cell Mater 20: 121-133.

Glaeser JD, Geissler S, Ode A, Schipp CJ, Matziolis G, Taylor WR, Knaus P, Perka C, Duda GN, Kasper $\mathrm{G}(2010)$ Modulation of matrix metalloprotease-2 levels by mechanical loading of three-dimensional mesenchymal stem cell constructs: impact on in vitro tube formation. Tissue Eng Part A 16: 3139-3148.

Jones EA, Kinsey SE, English A, Jones RA, Straszynski L, Meredith DM, Markham AF, Jack A, Emery P, McGonagle D (2002) Isolation and characterization of bone marrow multipotential mesenchymal progenitor cells. Arthritis Rheum 46: 3349-3360.

Jones EA, English A, Kinsey SE, Straszynski L, Emery P, Ponchel F, McGonagle D (2006) Optimization of a flow cytometry-based protocol for detection and phenotypic characterization of multipotent mesenchymal stromal cells from human bone marrow. Cytometry Part B (Clinical Cytometry) 70B: 391-399.

Ode A, Duda GN, Glaeser JD, Matziolis G, Frauenschuh S, Perka C, Wilson CJ, Kasper G (2010) Toward biomimetic materials in bone regeneration: functional behavior of mesenchymal stem cells on a broad spectrum of extracellular matrix components. J Biomed Mater Res A 95: 1114-1124. 